Portland State University

PDXScholar

10-1997

\title{
A Multi-Method Inquiry Into Managerial Coaching
}

Deborah J. Petricek

Portland State University

Follow this and additional works at: https://pdxscholar.library.pdx.edu/open_access_etds

Part of the Psychology Commons

Let us know how access to this document benefits you.

\section{Recommended Citation}

Petricek, Deborah J., "A Multi-Method Inquiry Into Managerial Coaching" (1997). Dissertations and Theses. Paper 5739.

https://doi.org/10.15760/etd.7610

This Thesis is brought to you for free and open access. It has been accepted for inclusion in Dissertations and Theses by an authorized administrator of PDXScholar. Please contact us if we can make this document more accessible: pdxscholar@pdx.edu. 


\section{THESIS APPROVAL}

The abstract and thesis of Deborah J. Petricek for the Master of Science in

Psychology were presented June 11 1997, and accepted by the thesis committee and the department.

COMMITTEE APPROVALS
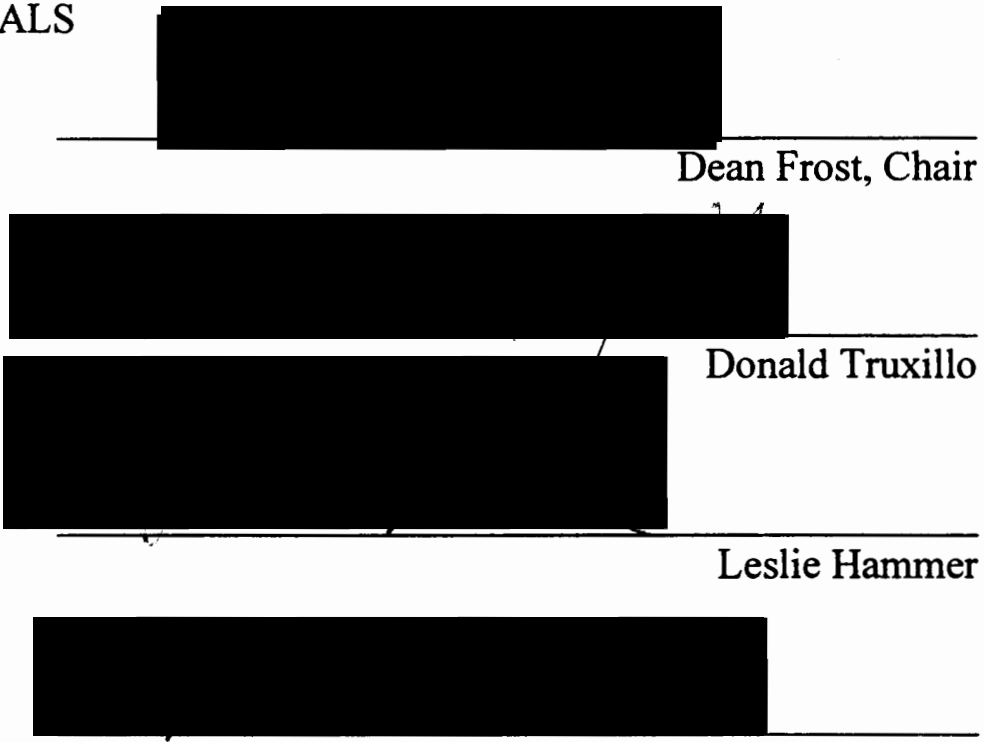

Robert Eder, Representative of the Office of Gradutate Studies

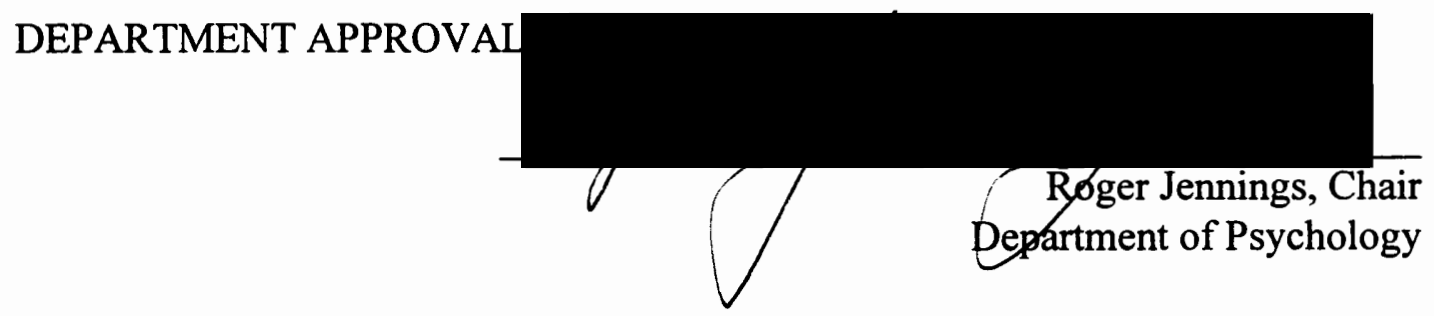

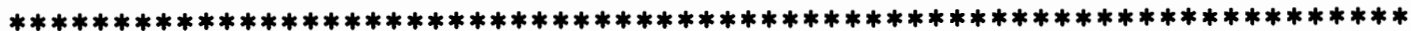

ACCEPTED FOR PORTLAND STATE UNIVERSITY BY THE LIBRARY

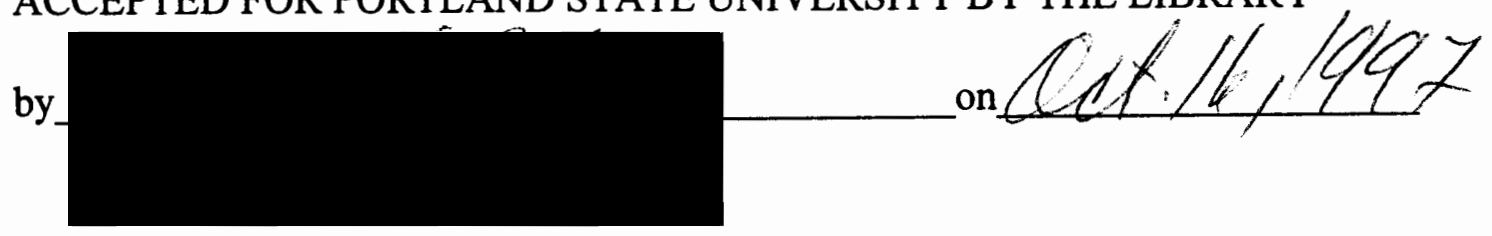




\begin{abstract}
An abstract of the thesis of Deborah J. Petricek for the Masters of Science in Psychology presented June 11, 1997.
\end{abstract}

Title: A Multi-Method Inquiry Into Managerial Coaching

Managerial coaching is a little understood and assessed phenomenon. An exploratory study was conducted in order to describe and examine coaching practices in the work world. Interviews were conducted with a group of managers and direct reports from a single company. Based on the interview discourse and previous research, two scales were developed in order to investigate the coach and coachee domains. Manager and associate survey forms were constructed using these new scales and the Leader/Member Exchange (LMX) in order to investigate the relationship domain of coaching. In addition, the Least-Preferred Co-worker (LPC) scale was included in the manager survey form in order to examine the role of leadership style in coaching. Dual responses for each of the three domain scales were collected in order to examine present and ideal perspectives of coaching experiences. Surveys were either distributed directly, or through human resource agents, to 188 potential survey respondents across select companies. Nineteen associates and thirteen managers representing fourteen different companies participated by returning their completed forms. 
Significant findings illustrated that the present and ideal scales were used differently in that ideal ratings were consistently higher than present ratings of coaching. In addition, it was demonstrated that associates tend to base assessments of their coaching experiences on their perceived quality of relationship with the coach. Finally, the quality of relationship between the coach and associate, as measured by the LMX scales, appears to be a better predictor of coaching success than coaches' leadership styles, as measured by the LPC scale. 


\author{
by \\ DEBORAH J. PETRICEK
}

A thesis submitted in partial fulfillment of the requirements for the degrees of

\title{
MASTER of SCIENCE \\ in PSYCHOLOGY
}

Portland State University

1997 


\section{ACKNOWLEDGMENTS}

First, I would like to extend my gratitude to both the initial liaison who helped me gain access to the interview participants and the succeeding liaison who linked me with other key contacts. Secondly, this research could not have been accomplished without the cooperation of the interview and survey participants. The manager and direct report interview participants volunteered candid and articulate accounts of their coaching experiences. Their contributions helped to illustrate coaching that occurs in their work environment plus affirm some of the assertions made in the research literature. Likewise, the sincere efforts of survey participants helped to support the study and affirm general concepts of coaching. Collectively, the participants have helped to clarify important aspects of coaching and directions for future research.

Finally, I'd like to acknowledge the faculty members who provided advice, support and encouragement throughout my research project. I was fortunate that my committee chair and members provided sufficient structure and direction as needed, yet granted me the flexibility I needed to accomplish this endeavor. In addition, I want to thank Talya Bauer for the generous flow of feedback and research leads. A last note of appreciation goes to Thomas Kinderman for his contributions to this study; his levels of interest and enthusiasm for coaching in the workplace was inspiring. 


\section{TABLE OF CONTENTS}

Acknowledgment . . . . . . . . . . . . . . ii

List of Tables $\ldots \ldots \ldots \ldots \ldots \ldots \ldots$ iii

Introduction $\ldots \ldots \ldots \ldots \ldots \ldots \ldots \ldots \ldots$

Traditions in Managerial Coaching . . . . . . . . . 2

Summary ................. 5

The Links Between Managerial Coaching and Managerial Leadership . . . . . . . . . . . . . . . . . 7

Basic Managerial Leadership Function . . . . . . . . . 8

Basic Managerial Coaching Functions . . . . . . . . 8

The Common Link: Task and Relationship . . . . . . . . 9

Empirical Studies of Managerial Coaching . . . . . . . . 10

The Stowell Coach Model . . . . . . . . . . . . . . 10

The Graham, Wedman \& Garvin-Kester Coach Model. . 11

Variant Expressions of Successful Coaching . . . . . . . 13

Theoretical Support . . . . . . . . . . . . . . . . . 14

Developing Coaching Measures $\ldots \ldots \ldots \ldots \ldots \ldots$

Multi-Domain Construct . . . . . . . . . . . . 17

Unit of Analysis . . . . . . . . . . . . . . 18

Survey: Dual Roles/Dual Raters . . . . . . . . . . . . 18

Scales: Two Versions . . . . . . . . . . . . . . . . . 19

Summary of Purpose . . . . . . . . . . . . . . . . . 19

Method . . . . . . . . . . . . . . . . . . 21

Interview Stage . . . . . . . . . . . . . . 21

Content Analysis . . . . . . . . . . . . . . . 25

Survey Stage . . . . . . . . . . . . . . . . 27

Measures . . . . . . . . . . . . . . . 30 
Results ...................... 36

Analysis . . . . . . . . . . . . . . . . 36

Qualitative Component: Interview and Content Analysis . 36

Quantitative Component: Survey Results . . . . . . . . 43

Discussion . . . . . . . . . . . . . . . 50

Interview/Content Analysis . . . . . . . . . . . . 50

Survey Study . . . . . . . . . . . . . . . 54

References ...................... 74

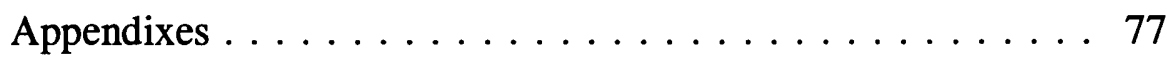

A The Primary Functions of Managerial Leadership

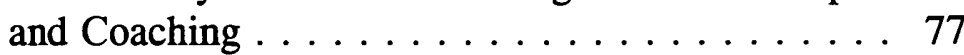

B Manager Survey Form . . . . . . . . . . . . . . 79

C Associate Survey Form . . . . . . . . . . . . . . 83

D Content Analysis/Coaching Framework . . . . . . 887

E E-mail Request for Research Participants . . . . . . . 89

F Informed Consent: Interview Stage . . . . . . . . . 991

G E-mail Announcement of Survey Study . . . . . . . 93

$\mathrm{H}$ Protocol of Initial Interview Agenda . . . . . . . . . 94

I Internal Subject Matter Experts' Sorting . . . . . . . 96

J Flyer/Request for Survey Participants . . . . . . . . 9 98

K Informed Consent: Survey Stage . . . . . . . . . . . 99

L Survey Instruction Page . . . . . . . . . . . . . . 101

M Demographic Questionnaire . . . . . . . . . . . 103

$\mathrm{N}$ Corresponding Coaching and Management

Practices. . . . . . . . . . . . . . . . . . . . . . 105 


\section{LIST OF TABLES}

Table

page

$1 \quad$ Means and Ranges of Managers' and Associates'

Demographics. . . . . . . . . . . . . . . . . .

2 Intercorrelations Among Important Organizational and Coaching Demographics of Managers . . . . . . . . . . . . 66

3 Intercorrelations Among Important Organizational and Coaching Demographics of Associates . . . . . . . . . . . .

6 Manager Survey: Intercorrelations Among New and Previous Scales . . . . . . . . . . . . . . . . . . . . . . . . 70

7 Associate Survey: Intercorrelations Among New and Previous Scales . . . . . . . . . . . . . . . . . . . . . . . 70

8 Paired t tests: Mean Differences of Mean Scores of Matched Present and Ideal Scales . . . . . . . . . . . . . . . . 71

9 Independent Sample t tests with Managers' LMX Low/High Quality of Relationship Groupings and Coaching Ratings . . . . 


\section{A Multi-Method Inquiry Into Managerial Coaching}

Managerial coaching, an on-the-job training strategy believed to enhance employee performance, is increasing in popularity (Graham, Wedman, \& Garvin-Kester, 1993, 1994). Yet, in spite of its appeal, many questions about coaching remain unanswered. To begin with, there is not a consensus on what coaching is and what its purposes are (cf. Bass, 1990; Evered \& Selman, 1989; Graham et al., 1993, 1994; Stowell, 1988). Also, it is unclear how individuals and organizations benefit from coaching (Evered \& Selman; Orth, Wilkinson, \& Benfari, 1987). Even more fundamental is the question of whether managerial coaching is different from general management practices. Therefore, an indepth examination of managerial coaching would help increase our understanding of the phenomenon and its utility to organizations.

The coaching literature is replete with unique descriptions and explanations of coaching. However, empirical studies are few. Under these circumstances the correspondence between concepts and realities of coaching is uncertain. Does the research literature reflect a realistic notion of coaching? Does coaching really exist in the workplace? Which concepts and explanations best describe the coaching that does take place? What is the fundamental purpose of coaching? In order to answer such questions accounts of coaching from the work world are needed. 
The main purpose of the present study was to explore perceptions of coaching in the work world. The primary objectives were to identify important indicators of successful coaching and develop a measurement for assessing coaching. This was achieved by first conducting interviews with a small group of managers and direct reports, and then performing a content analysis on the interview discourse. Next, based on this inductive analysis, questionnaires were developed that surveyed a larger number of managers and direct reports about their experiences and values of coaching. Finally, statistical analyses were performed on the survey data in order to further investigate the participants' perceptions of coaching. The research results helped to illustrate the differences in actual and desired coaching as well as managers' and associates' perspectives of successful coaching. The findings have contributed to the empirical understanding of coaching and illustrated a link to leadership theory. The following overview of managerial coaching helps support assumptions and concepts set forth in the present study.

\section{Traditions in Managerial Coaching}

Coaching has been acknowledged as a training technique in the context of management development since 1950 (Evered \& Selman, 1989). It has evolved from a superior's responsibility to develop a subordinate through a masteryapprentice relationship to a broader, more motivational, management development approach in the spirit of "sports coaching" popular in the 70s 
(Evered \& Selman). Early coaching traditions were practiced in order acknowledge and advance promising managers (Evered \& Selman; Orth et al., 1987). More recently, coaches have been instrumental in developing a breadth of lower level managers as well as subordinates (Evered \& Selman; McKenzie, 1989; Orth et al.; Stowell, 1988). Furthermore, the more pervasive nature of coaching relationships within an organization was conveyed by Stowell who suggested that coaching is a means of transferring leadership functions to a more experienced and educated workforce who aspire to contribute and grow. Thus, a shift in coaching relationships, from esoteric to more ubiquitous or vertical to horizontal, is apparent.

Parallel to this shift in the coaching relationship is a shift in management paradigms, namely, from a "management by control" to a "management through empowerment" intention (Evered \& Selman, 1989). Historically, vertical coaching relationships reflected the conventional "management by control" intention. According to Evered and Selman, a boss "coached" an employee only once a year during an annual review, which may be viewed as a tactic of control more than development. Even from a motivational orientation, coaching relationships reflected a "management by control" intention to the extent that a superior customarily directed an employee to higher levels of performance (Evered \& Selman) In contrast, a more recent description of coaching portrays the "management through empowerment" intention. Evered and Selman have 
described the more horizontal coaching relationship as an ongoing committed partnership between an individual and a manager who focus on discovering actions that enable and empower the individual to contribute more fully, productively, and with less alienation than experienced under the earlier control model.

Other current descriptions of coaching have elaborated on the more mutual and empowering qualities of the dyadic relationship. McKenzie (1989) described coaching as an interactive process where a manager and subordinate collaborate in order to extend the latter's current skills or develop new ones. Orth et al. (1987) described effective coaching as free and open exchange of ideas in a climate that is perceived by both partners to be a growth environment. Furthermore, coaching has been recognized as a powerful vehicle for creating a sense of partnership, entrepreneurial zeal, deep dedication, and team atmosphere among potential leaders (Stowell, 1988).

Concurrent with the changes in the nature of coaching relationships and management orientations, corporate intentions of coaching have become more diverse. Conventionally, coaching has been implemented by companies in order to foster subordinate career development and improve employee involvement and performance (Evered \& Selman, 1989; Graham et al., 1993, 1994; McKenzie, 1989; Stowell, 1988). Beyond developing careers and enhancing performance, Stowell (1988; p. 34$)$ stressed that managerial coaching has been recognized as a 
means to "invigorate organizational work spirit" in a more complex and dynamic workplace. More specifically, coaching has been implemented in order to develop positive climates of communication, systems of ongoing performance observation and feedback, and a general sense of leadership, partnership and enterprise (Stowell).

It is evident that coaching interventions have contributed to changes in significant work relationships and in how managers and subordinates relate (Graham et al., 1993, 1994). Roles and tasks appear to be more equitable between managers and subordinates. Managerial coaching promotes mutual, one-on-one relationships between managers and subordinates and supports a dayby-day, hands-on process of attaining knowledge and developing skills in more dynamic work settings (Orth et al., 1987). Yet, few efforts have been made to examine these features of coaching.

\section{Summary}

According to the literature, it appears that coaching has become more of a complex and common organization development intervention. A coach has become more of an explicit role assigned to a host of lower level managers rather than an implicit position assumed by a few executives. Consequently, the number of coaching relationships is increasing. In addition, these relationships are more mutual or horizontal in structure in that coaching partners tend to be more similar in status and interdependent (Stowell, 1988). By helping 
subordinates develop and improve, managers can improve their own capabilities and performance as well (Orth et al., 1987; Stowell). Ultimately, the reputations, chances for promotion, and power may be enhanced for both partners (Orth et al.).

Thus, coaching is not a one-sided transmission of knowledge, information, advice, and support. Nor is effective coaching simply an execution of a specific set of skills and behaviors performed by a coach. Coaching is a collaborative effort between two employees who develop a mutual relationship in order to enhance both of their work/career experiences. Yet, researchers have typically examined the singular coach role in order to assess coaching (e.g., Graham et al., 1993, 1994; Stowell, 1988). Therefore, a more comprehensive investigation of coaching is needed that examines both the coach and coachee roles. This would permit an investigation of the more equitable and mutual behaviors and attributes that contribute to the success of the one-on-one relationship. Conducive to exploring coaching and developing coaching measures of this nature are precepts of managerial leadership. 
The Links Between Managerial Coaching and Managerial Leadership

The references to leadership in the previous text are not coincidental. Management, leadership, and coaching have been used interchangeably in the organizational behavior literature. Some believe leadership to be a chief element of coaching (Orth et al., 1987) or management (Fiedler, 1978; Vecchio, 1987). Others endorse coaching as an essential ability of leaders (Stowell, 1988) or the heart of management (Evered \& Selman, 1989).

Clearly these concepts overlap. In Koontz and O'Donnell's textbook, Principles of Management, as cited by Evered \& Selman (1989), managing was defined "as the design or creation and maintenance of an internal environment in an enterprise where individuals, working together in groups, can perform efficiently and effectively toward the attainment of group goals". Leadership has been defined as a group function, that is, a task performing unit with a purpose that pivots around the clarification or setting of goals and pursuit of goal attainment (Frost, 1993). This definition applies to coaching to the extent that coaching involves a fundamental unit or group of two individuals. McKenzie (1989) has defined coaching as a relationship where a manager and a subordinate work together to accomplish mutual goals. Thus, management, leadership and coaching are alike in that they all involve a social unit whose members work together toward setting and attaining mutual goals. 


\section{Basic Managerial Leadership Functions}

This overlap can be further explained by a review of the literature describing leadership behaviors. Two leadership styles, as seen in Appendix A, the initiating structure and consideration orientations, have been widely accepted categories of management styles (Schriesheim \& Kerr, 1974; Vecchio, 1987) and also referred to as task and relationship orientations, respectively. A taskoriented manager focuses on task performance and completion by emphasizing role definition and initiating structure in order to clarify and attain group goals (Fleishman \& Peters, 1962). In contrast, a relationship-oriented manager focuses on group cohesion or maintenance by showing consideration of subordinates feelings and fostering job relationships where mutual trust and respect for subordinates' ideas are a priority (Fleishman \& Peters). These two orientations represent the two basic managerial leadership functions.

\section{Basic Managerial Coaching Functions}

Primary coaching operations have been described in managerial leadership terms as well. McKenzie (1989; p. 19) claimed that "great leaders are great coaches first because they have to learn to manage both business and human needs. . . . coaches have to achieve a fine balance between being supportive and caring, and being directive and clear". Moreover, the author described coaching in the context of comparing three primary management development techniques, that is, counseling, mentoring and coaching. Each technique is distinguished in 
terms of its emphasis on task versus relationship-oriented behaviors. In counseling, task behaviors are dominant; in mentoring, relationship behaviors are dominant; and in coaching, an equal balance is maintained between the task and relationship behaviors (McKenzie). Thus, task and relationship-orientated behaviors may also represent the basic functions of managerial coaching. The Common Link: Task and Relationship Functions

The classic task and relationship-oriented functions appear to be a fundamental link between managerial leadership and coaching practices. Although this link has not been empirically tested in the coaching research, authors have alluded to the connection between coaching practices and task and relationship-orientations of managers (e.g., McKenzie, 1989; Schelling, 1991; Stowell, 1988). A review of the managerial coaching literature has revealed a small body of research in which the basic managerial leadership functions appear to be integral elements in the assessments of coaching. 


\section{Empirical Studies of Managerial Coaching}

The most rigorous of efforts to define and measure coaching were two studies that demonstrated the extent to which variable degrees of leadershiporiented dimensions can provide a framework for assessing coaching practices (i.e., Graham et al., 1993, 1994; Stowell, 1988). In both studies coaching practices were inductively analyzed. In each case data were gathered through qualitative measures like interviewing and questionnaires and then interpreted. In spite of their experimental design limitations, these studies bear some evidence of the leadership nature of coaching.

\section{The Stowell Coach Model}

Stowell (1988) investigated the leadership ability of coaches in order to identify the most important coaching behaviors (see Appendix A). The focus was on the problem solving and performance dialogues between leaders and employees under difficult conditions in order to identify the most effective and ineffective coaching practices. Data were gathered from observations of actual coaching discussions, recounted coaching episodes, and semi-structured interview questions. Forty-seven coaching behaviors were identified and categorized into three categories which mirror the conventional leadership dimensions.

The model of coaching behaviors that emerged include two categories that appear analogous to the classic task and relationship dimensions, as well as a 
category that represents adverse managerial behaviors. Relationship-oriented skills like words and actions that show consideration for others were labeled supportive behaviors (Stowell, 1988). Task-oriented skills like initiating structure for employee actions and problem solving were labeled initiating behaviors (Stowell). Also, a third label, nonsupportive behaviors, was assigned to behaviors associated with managerial expressions of aggression and power (Stowell). Results indicated that high levels of supportive behaviors, low levels of nonsupportive behaviors, and moderate amounts of initiating structure were characteristic of effective coaching. Although this framework was not examined for structural validity or reliability, it offered evidence of task and relationship dimensions of coaching.

\section{The Graham, Wedman \& Garvin-Kester Coach Model}

Graham et al. $(1993,1994)$ investigated the effects of a coaching skills training for managerial coaches. The focus was on Schellings (1991) eight coaching skills which were used as criteria for rating the effectiveness of coaches before and after training. As arranged in Appendix A, these eight coaching skills parallel the managerial leadership skills. Communicating clear performance objectives and providing regular performance feedback appear similar to the task-oriented skills of a managerial leader. Likewise, building a warm, friendly relationship and providing help, training, and guidance appear similar to the relationship-oriented skills of a managerial leader. However, 
while Stowell (1988) had an explicit emphasis on leadership, the leadership orientation of Graham et al. was much more subtle. Although the authors acknowledged that coaching may be an important part of sales management and leadership in general (Graham et al.), the descriptions and constructs of coaching were not couched in leadership terms.

Graham et al. $(1993,1994)$ conducted interviews before and after a training program in order to obtain a pre and post-test measure of coaching behaviors. The authors gathered and assessed accounts of coaching episodes or observed changes in coaching as well as demographic information based on Schelling's (1991) eight coaching behaviors (see Appendix A). Both the before and after measures indicated that successful coaching was attributed primarily to taskoriented behaviors. In the pre-training measure a majority of task-oriented skills indicated successful coaching. Likewise, in the post-test measure, a majority of the task-oriented behaviors significantly increased and consistently indicated successful coaching (Graham et al.).

Although these results were derived from statistical comparisons, the measures on which coaching behaviors were assessed were not examined for consistency, structural relationship, or relevance. Nevertheless, both the coaching framework and study results have exhibited a link between taskoriented skills and successful coaching. 


\section{Variant Expressions of Successful Coaching}

In contrast, the findings of Stowell (1988) and Graham et al. $(1993,1994)$ findings expressed successful coaching in varying degrees of leadership dimensions. Stowell examined the leadership ability of coaches under difficult conditions in order to identify optimal coaching behaviors. The author demonstrated that successful coaching was attributed primarily to a manager's relationship-oriented behaviors. In fact, the author emphasized that support behaviors were the centerpiece of coaching (Stowell). Graham et al. examined the transfer of newly learned coaching skills from both conventional and on-thejob training. The pre- and post-training measures of managers implied that taskoriented coaching behaviors were representative of successful coaching.

Stowell (1988) and Graham et al. $(1993,1994)$ investigated different situations of coaching and experienced different results. Stowell focused on important coaching skills in difficult situations and argued that this would be a true test of leadership ability. Under different circumstances, Graham et al. focused on the effect of training on coaching skills. Central to this latter study were coaching behavioral objectives intended to improve sales staff performance. Perhaps in this case, more attention was paid to the development of specific performance coaching skills than to general leadership skills. Consequently, the more task-dominated assessment of coaching may have been shaped by the training goals. In other words, different coaching situations or goals may 
account for the unique patterns of successful coaching behaviors described by the two studies.

\section{Theoretical Support}

Leadership theory may help explain variable descriptions of successful coaching. Researchers of managerial leadership have offered explanations for similar variations in describing leadership. According to Fiedler (1978), difficult situations (e.g., ambiguous goals and poor task structure) may tend to elicit a specific leadership style. This supports the notion that successful coaching may be attributed to varying degrees of task and relationship-oriented dimensions. Stowell's (1988) and Graham et al's. $(1993,1994)$ contrasting illustrations of successful coaching may be a genuine representation of the variable nature of successful coaching.

Fiedler's (1978) contingency theory suggests that leadership effectiveness is a function of the interaction between a manager's leadership style, or LPC, and the conditions of the situation according to the combined status of leader/member relations, task structure and leader position of power. When relations are good, tasks are highly structured and leader positions are strong, task-oriented leaders tend to be most effective. Task-oriented leaders also tend to be most effective in the converse conditions when relations are poor, tasks are unstructured, and the leader positions are weak. However, when relations, task structure, and leadership position are of moderate conditions, relationship- 
oriented leaders tend to be most effective. Therefore, in as much as coaching appears to be both a task and relationship-oriented phenomenon, a coach's dominant leadership style may affect the quality of his/her coaching. Thus, leadership style may be another critical component of a coaching assessment. 


\section{Developing Coaching Measures}

In sum, ample definitions and a dearth of construct validity evidence suggest that coaching remains an ambiguous phenomenon. With regard to a coaching investigation, important coaching assessment criteria have become apparent. Conventionally, successful coaching has been represented by certain acquired skills of a coach. Yet, more current perspectives of management and coaching suggest that supervisor/subordinate relationship roles are more mutual and interdependent. In addition, the Stowell (1988) and Graham et al. (1993, 1994) studies exhibited that varying degrees of leader behaviors have described successful coaching. Insights from contingency theory suggest that leadership dimensions and styles may explain variable, and sometimes contrasting, descriptions of successful coaching. Therefore, multiple aspects of coaching must be examined when assessing coaching. In sum, the dual coaching roles as well as leadership dimensions and styles are critical components of a coaching assessment.

Another leadership theory offers further support and means of assessing multiple aspects of coaching. Leader/Member Exchange (LMX) theory, based in role and social exchange theories, acknowledges the mutual nature of leader/member relationships and suggests that the quality of such relationships varies depending on the interaction within a dyad (Graen \& Uhl-Bien, 1995; Liden \& Maslyn, in press; Sparrowe \& Liden, in press). The quality of 
coaching relationships may be subject to similar notions. The coaching dyad can be described as a social exchange between two employees who take on partnership building roles in order to develop a mutual relationship that enhances both of their work experiences. Thus, the quality of this interactive relationship is another important component of coaching to be investigated.

\section{Multi-Domain Constructs}

Graen and Uhl-Bien (1995) advocated that researchers concurrently examine three primary leadership domains, the leader, the follower and the relationship. The authors believed that multiple-domain research should help better explain what contributes to effective leadership (Graen \& Uhl-Bien). Graen and UhlBien reported that several unpublished dissertation studies generated significant predictable variation in leadership outcome when the three domain variables in combination were examined. An assessment of coaching could benefit from the application of such a construct. Therefore, in addition to the two coaching domains, a third domain, the coaching relationship, was incorporated into the research design. The Leader/Member Exchange (LMX) scale (see Appendixes B \& C) which examines the quality of relationship between a supervisor and subordinate was used to measure the relationship domain. In addition, in order to obtain a measure of a coach's leadership style, the Least Preferred Co-worker (LPC) scale (see Appendix B) was included in this study. 


\section{Unit of Analysis}

By convention, many of the leadership materials have been based on group leadership. In terms of coaching, a coach has been described as a leader of a group or team of workers (Evered \& Selman, 1989; Graham et al., 1993, 1994) or as a leader in a one-on-one relationship (Orth et al., 1987). Because the present researcher has focused on the dual roles and relationship of coaching partners, the exploration of managerial coaching was based on the one-on-one leadership format. However, due to the fact that paired, matched dyads were unavailable for the study, the analysis was performed on group, (i.e., aggregated) data for each of the coaching domains.

\section{Survey: Dual Roles/Dual Raters}

Because coaching is a mutual phenomenon, both roles were investigated. Likewise, both the coach and coachee groups rated coaching practices. This required two survey forms, a manager form for coach respondents, and an associate form for coachee respondents (see Appendixes B \& C). Managers self-reported on the coach and relationship domains, plus their leadership style. In addition, they reported on the "other" role, or coachee domain. Conversely, associates reported on the "other" role, or coach domain, and self-reported on the coachee and relationship domains. 


\section{$\underline{\text { Scales: Two Versions }}$}

Because coaching practices tend to be more implicit than explicit, in this study it was important to identify actual coaching practices and experiences. For the same reason, it was important to identify desired coaching practices and experiences. Therefore, two different viewpoints of coaching were assessed (see Appendixes B \& C). The present and ideal perceptions for each of the coaching domains were rated by both the coach and associate in order to capture perspectives of "the way it is", or current coaching experiences, and "the way it should be", or ideal coaching experiences.

\section{Summary of Purpose}

Little empirical research has been conducted in order to describe and assess managerial coaching. The intent of this study was to investigate work world perceptions of coaching practices and develop a coaching assessment tool that reflects the beliefs and needs of coaching partners. In order to access work world perspectives, interviews were conducted with volunteer managers and direct reports from a single work environment. Plus, coaching experts from the same company as well as external coaching experts were interviewed.

Leadership constructs were applied to the survey design in order to investigate the coach, coachee and relationship domains of coaching. In addition, in order to examine the role of leadership style in coaching, the LPC scale was included in the study. Two survey forms were developed in order to compare managers' 
and associates' perspectives of coaching. Also, present and ideal versions for each of the coaching domains were gathered in order to compare differences in actual and desired coaching practices. 


\section{Method}

Although the data collection and analysis were iterative processes, this study can be outlined in three stages. In the first stage, interviews conducted with managers and direct reports (associates) helped to explore collective perceptions of coaching practices and experiences. These interviews were recorded and transcribed. In the second stage, a content analysis was performed on the interview discourse according to the approaches used by Lincoln and Guba (1985), Lofland and Lofland (1995), and Marshall and Rossman (1995). Data collected throughout the interviews were organized into a framework that best summarizes the coaching concepts and practices expressed by the participants (see Appendix D). Based on this framework, in the third and final stage, a survey (see Appendixes B \& C) was designed to gather data from a larger sample of managers and direct reports in order to conduct an empirical investigation of coaching.

\section{Interview Stage}

Participants. Four managers and three direct reports from a local computer company volunteered to participate in the interview stage of the research project. All four managers classified themselves as middle-management. Also from the same company, four executives were identified by peers as experts on coaching to participate in the interview stage. In addition, two external consultants identified by the researcher as experts on coaching were interviewed. 
Procedures. Initially, a liaison within the company solicited managers corporate wide by means of e-mail correspondence that announced the research project and invited their participation. Contents of this correspondence can be seen in Appendix E. Out of three responses, two managers agreed to participate in the interview stage. A second e-mail correspondence, similar to the first, was sent two weeks later. This time, one manager out of six who responded agreed to participate. In the course of interviewing a direct report, a fourth manager was recommended. When contacted by the researcher, this manager also agreed to participate in the interview stage.

One-on-one interviews were conducted with the participating managers. Two local managers were interviewed face-to-face, and two remote managers were interviewed by telephone. Each local manager was presented with the voluntary consent form at the onset of the first interview (see Appendix F). The researcher cited the main points of the document and then allowed time for the participant to read and sign the form before the interview commenced. The remote managers received, signed and returned a consent form in advance of their first interview.

After each of the four managers had been interviewed once, they were asked to inform their direct reports about the research study. The researcher supplied each manager with an e-mail message that informed their direct reports about the study (see example in Appendix G). The researcher's contact numbers were 
included in the message so that those interested in participating could contact her without disclosing the status of their participation to their managers. A total of three direct reports responded and agreed to be interviewed. One-on-one interviews were conducted with each direct report. One local direct report was interviewed face-to-face, and two were interviewed by phone. Voluntary consent forms were presented to the remote and local direct reports prior to their interviews just as they were to the remote and local managers.

Interviews with the managers and direct reports were scheduled in advance and conducted during work hours. Each manager was interviewed twice with the exception of one who was interviewed once. Interviews lasted approximately 45 to 90 minutes. Each direct report was interviewed once for approximately 45 minutes, plus subsequent interviews were conducted with each by means of e-mail correspondence.

Two internal coaching experts were also contacted in order to help clarify coaching concepts and practices. First, an executive director recommended by the liaison was interviewed twice for approximately 90 minutes. Then, this executive referred me to several peers believed to be experts on the subject of coaching. I met briefly with one in order to exchange information and resources about a corporate program on mentoring and the coaching study in progress with the company. At a later date, this peer was asked to categorize statements about coaching and then indicate the best measure(s) of coaching for each category. 
This task was also asked of two other recommended peers plus one of the middle-managers initially interviewed. All four agreed to the task; one completed the task and one other partially fulfilled the request.

Two external coaching experts were also interviewed. An organizational consultant and author on the topic of performance coaching was interviewed about coaching concepts and practices for approximately two hours. This consultant recommended that I meet with a research specialist associated with a state organization. In the specialist's absence, a two hour interview was conducted with one of his associates. Coaching measurement formats, contents and issues were the main topics of conversation.

All the interviews were semi-structured and the questions were open-ended to ensure that the participants were able to respond and contribute fully. Based on the coaching, managerial and leadership research literature, an agenda of questions was used as a point of departure for discussions. However, the purpose of the inquiry was to verify, not to impose, the elements of this agenda. Typical questions asked included: "When you hear the term managerial coaching, what does that mean to you?"; "What is your definition of coaching?"; and "When do you know coaching is occurring?". A protocol of initial interview questions can be seen in the Appendix $\mathrm{H}$.

As new information was generated from interview discourse, the agenda was modified. During each interview the researcher made notations. After each 
interview, the contents were reviewed and summarized, and the agenda was revised in preparation for subsequent interviews (see Lincoln \& Guba, 1985). Yet, attempts were made to remain consistent with the manner of questioning throughout the interview stage in order to compare and contrast data across participants. With each participant's permission, the interviews were recorded to assure accurate and thorough accounts of discourse. The tapes were transcribed and the field notes were reviewed and secured by the researcher.

\section{Content Analysis}

Procedures. The initial interview agenda generated discussions about global categories of coaching such as the meaning and purpose of coaching. Over time, more specific questions solicited descriptive explanations of what coaching was like in terms of behaviors and attributes of coaching partners. As information accrued across the coaching inquiry, comments that were repeated among the participants, similar to that found in the literature, or otherwise considered important were organized into main categories or units of coaching (see Lofland \& Lofland, 1995; Strauss \& Corbin, 1990). For example, recurrent interview contents were compiled into units like "practices" which represented talk or action; "roles" which represented attributes or characteristics; and "relationships" which represented how partners connected and interacted.

Based on the categories identified, 235 statements about coaching were compiled. Then the sorting process was reversed and several attempts were 
Managerial Coaching 26

made to organize these statements into dimensions and categories of coaching from different perspectives. This provided the researcher opportunities to evaluate alternative explanations of the content analysis (see Lofland \& Lofland, 1995; Marshall \& Rossman, 1995; Strauss \& Corbin, 1990). In addition, results helped to refine the number of important statements for scale contents. Two internal coaching experts were asked to classify the statements into categories, name the categories, and then identify the best measures (statements) for each. One grouped the statements into 12 categories and the other grouped the statements into four categories. While comparing their identified categories and measures, I noted that the latter four category grouping seemed to represent broader dimensions of coaching. As seen in Appendix I, I integrated their work into a framework which appears to reflect their unique corporate culture and language.

At this stage of the content analysis, I had become sensitive to several issues that influenced the subsequent development of the coaching scales. First of all, due to the voluntary nature of this study, the participants' contributions were time limited based on their work demands. Secondly, due to the small volunteer base obtained from a single company, it was apparent that I would need to recruit survey respondents from across companies. Thirdly, the internal coaching experts had not addressed the dual roles in their sorting of data. Finally, I had developed a bias in favor of a multi-domain construct. On all 
accounts, I elected to organize the data differently than the internal coaching experts had in order to represent a more general portrayal of coaching and address both coaching roles. Based on my own judgment, I integrated the important interview discourse, the categories and dimensions outlined by the experts, and previous research findings into what I determined to be the essence of the participants' sentiments of coaching (see Appendix D). In contrast to the experts' dimensions and categories (see Appendix I), this outline of coaching pointed to a different arrangement of dimensions and categories. However, due to the small sample size, neither set of dimensions and categories were explored. From the researcher's framework then, two coaching scales or questionnaires were developed in order to survey and assess perceptions of the coach and associate domains. The coach scale examined the manager who coaches and the associate scale examined direct reports or subordinates who are coached by a manager.

\section{Survey Stage}

Participants. Thirteen managers and nineteen associates participated in the survey study. The managers represented 7 companies, 6 main group functions, and 13 job titles. The associates represented 12 companies, 9 main group functions, and 15 job titles. All participants were of White, non-Hispanic origins and ranged between 30 and 59 years in age. The managers represented a range of lower, middle and upper management levels and all but one have been 
coached by a manager before. By job title, two participants who completed the associate form were identified as managers who were coached by their respective managers. Twelve of the associates had been coached by a manager before. As seen in Table 1, additional means and ranges of the participants' organizational and coaching experiences have been converted and rounded for easier reading.

Procedures. For the survey portion of the study, participants were recruited from companies considered to be innovative in the production or implementation of technology and/or innovative management practices. In order to solicit participation from a breadth of companies the survey study was marketed to old and new contacts. Both manager and associate survey forms were distributed to the interviewed managers and direct reports as well as the internal and external coaching experts. The two survey forms were also mailed to each member of the Business Educators Strategy Team (BEST), a consortium of training and development and human resources professionals from high-tech and fast-growth companies who had been informed about the research project by the liaison. In addition, other key contacts from a variety of companies listed in the 1991-92 "Resource Guide Oregon High Technology" and the 1995 "Advanced Technology in the Pacific Northwest Directory" were sent copies of the survey forms. These contacts had also been informed by the researcher about the study at its onset. Additional references made by the liaison, participants, key contacts and other word-of-mouth leads were presented with the survey packets 
as well. Some surveys were distributed through a local business consultant who offers performance coaching training to professionals. Finally, some surveys were distributed through a training and development discussion group on the internet.

Included with the research announcement and survey forms were flyers (see Appendix $\mathrm{J}$ ) that introduced the purpose, benefits and incentives of participating in the survey. In order to increase the chances of survey returns, lottery prizes that would appeal to the work group sample were offered. A total of 188 surveys were distributed, 75 to managers and 103 to associates. A total of 32 manager and associate survey forms were completed and returned.

The potential participants were asked to complete and return the surveys within 10 to 14 days. Voluntary Consent Forms (see Appendix K) were enclosed in each survey so that the participants were informed of their rights as volunteers and the promise of confidentiality. The form also explained that their refusal or acceptance to participate would not affect their relationships with their coaching partner, immediate supervisor, or employer. Included in the front of each survey was a document (see Appendix L) that explained the main purpose of the study, instructed how to complete and return the survey, and posted the researcher's name and phone number. This document was kept by each participant so he/she may contact the researcher for clarification or additional information (one participant contacted the researcher for clarification). In 
agreement, each participant signed the consent form, completed the survey, and returned them both in an enclosed, pre-addressed and stamped envelope to the researcher within the designated time frame. Upon receipt, the researcher protected each participant's confidentiality by separating the consent forms from the remaining sections of the survey.

\section{$\underline{\text { Measures }}$}

Survey format. Two different survey forms were developed in order to investigate manager and associate perspectives of coaching independently. In the manager form (see Appendix B), responses were solicited from coaches. In the associate form (see Appendix C), responses were solicited from direct reports or subordinates who receive coaching. In the manager and associate survey forms, statements of coaching were organized into 5 and 4 sections, respectively (see Appendixes B \& C). For both forms, the first 4 sections were virtually the same set of questionnaires: Section 1 was the demographic questionnaire;

Section 2 was the coach domain scale; Section 3 was the associate domain scale; and Section 4 was the relationship domain scale. Section 5 of the manager survey form consisted of the Least Preferred Co-worker (LPC) scale on which managers' leadership styles were determined.

Although the respective manager and associate scale items were essentially the same sets of questions, statements were presented from either the coach (manager survey form) or associate (associate survey form) perspective. In 
addition, because managers tend to have multiple coaching relationships, those completing the manager form were asked to respond to statements of coaching in terms of their current general coaching experiences. In contrast, associates were asked to respond to statements of coaching in terms of their current experience with their respective managers. For example, managers were asked to selfreport on their current role as coach, whereas associates were asked to report on their current experience of the their coach. Conversely, managers were asked to report on their current experience of the associate role in general and associates were asked to self-report on their role as the coachee. With regard to the relationship domain, each group was asked to report on the quality of the coaching relationship experienced from their own perspective.

Section 1: Demographic questionnaire. This questionnaire gathered demographic data such as employee tenure, level of education, and job titles (see Appendix M). Solicitations from the managers and associates were nearly identical. The questions varied for the two groups in only a few cases with regard to organizational and/or coaching experiences. For instance, managers were asked about their span of control and associates were asked whether they have ever coached someone else before. The data were used primarily for sample description. However, demographic correlations were examined in order to identify important variables of coaching for future research. 
Section 2: Coach scale. A measure of coaching was developed that focuses on the behaviors and attributes as they apply to the coach role (see Appendixes B \& C). Based on the information gathered from the interviews and previous research, 32 items were used to assess the two groups' perceptions of the coach behaviors and attributes. For example, managers were asked to self-report on their role as coach, whereas associates were asked to report on their experience of their coach.

Coach Behaviors and Attributes Scale: The Way It Is. This 32-item scale was used to measure present coaching experiences of the coach role in order to examine perceptions of current coaching practices (see Appendixes B \& C). Both managers and associates were asked to indicate to what extent an item reflects their present coaching experiences. Each item was rated on a five-point scale ranging from 1 (not at all) to 5 (to a very great extent).

Coach Behaviors and Attributes Scale: The Way It Should Be. The same 32-item scale was used to measure desired coaching experiences of the coach role in order to examine perceptions of ideal coaching (see Appendixes B \& C). Both managers and associates were asked to indicate how important an item was as a measure of effective coaching. Each item was rated on a five-point scale ranging from 1 (not at all important) to 5 (very important).

Section 3: Associate scale. A measure of coaching was developed that focused on behaviors and attributes as they apply to the associate role (see 
Appendixes B \& C). Based on the information gathered from the interviews and previous research, 23 items were used to assess the two groups' perceptions of the associate behaviors and attributes. For example, managers were asked to report on their general perceptions of the coach role, whereas, associates were asked to self-report on their role as coachee.

Associate Behaviors and Attributes Scale: The Way It Is. This 23-item scale was used to measure present coaching experiences of the associate role in order to establish a baseline of current coaching practices (see Appendixes B \& C). Both managers and associates were asked to indicate to what extent an item reflects their present coaching experiences. Each item was rated on a five-point scale ranging from 1 (not at all) to 5 (to a very great extent).

Associate Behaviors and Attributes Scale: The Way It Should Be. The same 23-item scale was used to measure desired coaching experiences of the associate role in order to illustrate perceptions of ideal coaching (see Appendixes B \& C). Both managers and associates were asked to indicate how important an item was as a measure of effective coaching. Each item was rated on a five-point scale ranging from 1 (not at all important) to 5 (very important).

Sections 4 and 5: Leadership scales. Along with the new coaching scales, two existing scales were used in order to examine leadership aspects of coaching. In order to assess the quality of the coaching relationship a version of the Leader/Member Exchange (LMX) scale was used in section four of both 
forms (see Appendixes B \& C). In order to investigate the leadership style on coaching, the Least Preferred Co-worker (LPC) scale was included in section five of the manager survey form only (see Appendix B).

Leader-Member Exchange Scale (LMX)/Supervisor \& Member forms. The LMX measures the quality of exchange between supervisors and subordinates (Scandura \& Graen, 1984) which reflects a subordinate's level of needs for attention and support from a leader as well as level of contribution or commitment to shared goals and performance (Scandura, Graen, \& Novak, 1986). Cronbach's alpha of .86 has been reported (Scandura \& Graen, 1984) for the original version which is a seven item Likert-type scale on which scores are summed for each respondent resulting in a possible range from 7 (low quality of exchange) to 28 (high quality of exchange).

An 8-item variation of the original scale was used that has demonstrated a Cronbach's alpha of .94 on a sample of 317 supervisors and subordinates (see Bauer \& Green, 1996). Both leader and member forms of this 8-item scale were used in the manager and associate forms, respectively. However, these forms were uniformly modified in order to maintain the key words utilized in the original scale. As with the new coaching scales, the two forms of the LMX scale were also presented in two versions in order to assess both the present and ideal qualities of the coaching relationship (see Appendixes B \& C). For the present measure of coaching, each item was rated on a five-point scale ranging 
from 1 (not at all) to 5 (to a very great extent). For the ideal measure of coaching, each item was rated on a five-point scale ranging from 1 (not at all important) to 5 (very important).

Least Preferred Co-worker (LPC). Unlike the other scales, this measure was included in only the manager form of the survey, and participants responded only once to each statement (see Appendix B). This instrument reflects the leadership style of a supervisor (Fiedler, 1978), and was used in order to measure the leadership styles of the coach role. The LPC score indicates whether a leader uses a relationship-orientation (high-LPC), a task-orientation (low-LPC), or a mixed orientation (middle-LPC). Reported split-half reliability coefficients have ranged between .80 to .90 (Kennedy, 1982). The questionnaire consists of 16 items in the form of a semantic differential response dimensions. 
Results

\section{$\underline{\text { Analysis }}$}

This exploratory study resulted in two sets of analyses and outcomes. A qualitative component of this study permitted the researcher to investigate work world coaching concepts and practices from the perspectives of a group of managers and associates who work for the same company. This method of inquiry involved a content analysis of interviews with the participants from which a framework of coaching was constructed. Based on these findings, coaching scales were developed in order to conduct a coaching assessment survey on a larger sample of participants from different companies. A quantitative component of this study allowed the researcher to investigate the survey data through statistical analyses. This method of inquiry involved descriptive and inferential statistics in order to explore the data, examine the survey scales, and compare manager and associate perspectives of coaching. Qualitative Component: Interview and Content Analysis

Coaching experiences and beliefs were solicited from mangers and associates in order to investigate fundamental questions about coaching. Recurrent interview contents were organized into themes and topics and analyzed in order to understand the participants' shared meaning of coaching. These findings also helped to define additional research questions and speculate about other coaching issues. The following topics were the highlights of the analysis. 
Does coaching exist in the workplace? The managers and associates who were interviewed unanimously agreed that coaching did exist in their work environment. According to one manager, "a spirit versus a law. . ." of coaching existed in the work environment. However, this recognition of coaching was not attributed to any efforts on behalf of the company. This notion was counter to what I had anticipated because the liaison had shared some performance management tools with me that had been developed in order to prescribe and foster coaching practices within the company. Yet, participants were not aware of these support tools. Even when challenged, the interviewees insisted that they had not been predisposed to any coaching-specific training or materials in the present company that may have influenced their perspectives. In some cases, individuals attributed their understanding of coaching to other corporate environments in which they have worked.

What does coaching look like? Although coaching was not an active corporate program, the participants' descriptions and explanations of coaching appeared congruent. Even when geographically separated, the participating managers and associates shared similar notions of coaching. When asked to define and explain coaching, the mangers explained that coaching is, "ongoing conversations regarding performance feedback. . .", "[a] channel for feedback. . .", "helping to improve people's well-being and their effectiveness. . .", "casual conversations, interactions. . .", "helping people with their yearly flow and 
work cycle. . .". One direct report explained that coaching is, "a two-way phenomenon. ..". Another drew the analogy of when a, "manager steers and the direct report propels. . .". Clearly apparent in these comments is a mutual, interactive, one-on-one relationship that is based in communication.

What is the nature of coaching? The above cluster of explanations also suggests a very specific form of coaching. Up to this point, the term "managerial coaching" has been used by the researcher to distinguish it from other forms of coaching like sports, educational, or executive coaching. However, "performance coaching" appears to be a more accurate description of the nature of coaching depicted. The performance orientation was expressed in terms like "commitment to development" and "excellence in performance". Furthermore, the emphasis of coaching was more on present versus past performance issues, and to a lesser degree, on future performance (with regard to potential skills needed) versus long term career development. In addition, there was more of an emphasis on "process" versus "task" in that many of the participants expressed more concern with regard to the behaviors expected of associates than to the details of executing immediate tasks and goals. For example, managers felt it was important for associates to have an "understanding of what is right, this is how you do the job so know the requests and desires [managerial and customer expectations]. . ." and "talk about desired behaviors and performance versus goals. ..". These descriptions are in accordance with 
one author's description of coaching. Allenbaugh $(1983,1984)$ explained that in performance coaching the focus is on current performance and future needs and expectations in contrast to other forms of coaching that focus on long-term career needs or corrective discipline. Therefore, the type of coaching expressed by the interviewed sample may best be identified as performance coaching versus career, disciplinary, or executive coaching.

How does the literature compare with reality? Not only were the participants' perceptions congruent with each other, they were also congruent with much of the research literature (e.g., Evered \& Selman, 1989; Graham et al., 1993, 1994; Orth et al., 1987). In particular, their perceptions best matched Allenbaugh's (1994) view of coaching as "an ongoing collaborative process of providing direction, feedback and encouragement with the intent of enhancing the effectiveness of associates, self and the organization" (p. 2). In addition, their perceptions corresponded with Stowell's (1988) sentiments that coaching was a means to transfer leadership functions to a workforce who aspire to contribute and grow. This outlook was apparent in a couple of the managers' shared belief that multi-directional coaching, that is, conventional (downward), upward, or lateral, helped to create a climate of win/win among managers, associates and even clients. There was a common belief among the participants that associates should coach their internal and/or external clients in their areas of expertise. Furthermore and perhaps fundamental to the notion of multi- 
directional coaching, was the expressed need to cultivate in all employees a genuine concern about others' (clients inclusive) success and welfare at work.

How is coaching like leadership? A primary focus of this exploratory study was on the leadership aspects of coaching. To begin with, it was speculated that the classic leadership task and relationship-oriented behaviors might also be the basic functions of coaching. Although the interviewees did not render definitive answers to this question, the content analysis pointed to two primary themes of coaching, "performance development" and "rapport building". These dimensions appeared analogous to the task and relationship dimensions. However, the meanings associated with the performance and rapport orientations diverged from those of the conventional orientations. As previously addressed, the emphasis on performance development surrounded "commitment to development" and "excellence in performance" and appeared more process than task oriented. The emphasis on rapport building seemed to venture beyond building empathy and friendship to aspects like "quality of communication", "creating positive climates", and "showing respect".

Performance coaching practices. Specific activities cited by the participants appeared to represent a coherent perspective of performance coaching practices. Both managers and direct reports accounted for informal and formal meeting conversations, independent from performance reviews, where performance criteria and issues were discussed. Typical communications focused on 
clarifying , "managerial and customer expectations. . .", "what I expect - what he expects. . .", "desired behaviors and performance versus [job] goals. . .", "performance agreement and development plan. . .", "what was observed where they're performing well - where to focus. ..". These examples of coaching, like the explanations shared earlier, consistently portray a performance-oriented perspective of coaching practices.

Purposes and goals of coaching. An important issues was observed in the course of investigating the purposes and goals of coaching. On these topics, the managers' were more inclined to speak with regard to the associate role than their own role. Plus, the associates' contributions in these areas were minimal regardless of which role was the object of conversation. Managers' reasons for coaching and expectations for the associate role included, "for everyone to be self-directed and accountable for the job. . .", "to gain a sense of where need to go. . .", "to become responsible for own growth. . .", "to develop technical and social skills. . .". In contrast, the direct reports did not offer additional explanations of the purpose or goals of coaching. In fact, the few comments made by two direct reports who had the same manager were nearly verbatim to their manager's interview comments. Even when the questions were paraphrased and asked a second time, I failed to elicit a distinct perspective. These observations elevated my sensitivity about the overall differences between 
manager and associate responses to my questions as well as omissions of certain coaching elements in the interview discourse.

Coaching roles. In some areas the role of the coach was not thoroughly depicted, and by far, the associate role was lacking clarity. In response to the observations noted above, I reviewed the interview transcripts and noted an overall pattern of fewer and shorter comments made by the direct reports. Even subsequent probing failed to elicit more elaborate accounts of coaching experiences from their perspective. This underscored the fact that the associate role in coaching has been less examined and described than the coach role. Consequently, models of associate behaviors and attributes or prescriptions of accountability have not been available. On the flip side, some aspects of the coach role have not been clearly defined. These disparities seemed inappropriate for a relationship that consists of mutual roles, equitable skills, and dual benefits. In order to address these voids in the interview contents, concepts and excerpts from the coaching literature that helped to explain and fill the gaps were identified. This effort resulted in an outline of coaching that has described the dual roles involved (see Appendix D). In addition, the definition of coaching as well as the purpose and goals for both roles were summarized in this framework which reflects the essence of the interviews and the accent of the literature. 


\section{Quantitative Component: Survey Results}

Descriptive and inferential statistics were calculated in order to explore the survey data and examine additional research questions. In this quantitative stage, the inquiry focused on the quality as well as use of the new scales and the differences in the managers' and associates' perspectives of coaching.

Describing the research sample. Descriptive statistics were calculated on demographic variables of the survey participants in order to describe the research sample in more detail and identify important variables for future studies. As seen in Tables $2 \& 3$, correlations were calculated for both coach and associate demographics (see Appendix M). Among the intercorrelations for the managers' demographics, 5 pairs of variables are significantly correlated at $\underline{p}$ $<.05$ level. Among the intercorrelations for the associates' demographics, 8 pairs of variables are significantly correlated at the $\underline{p}<.05$ level. The most interesting of these highly related variables appeared to link organizational and coaching experiences. For instance, a manager's tenure and duration of current job position appeared to predict the length of a current coaching relationship. Specifically, a manager who was more experienced in a company and job position tended to have a longer, current coaching relationship with an associate. Plus, age appeared to predict whether a manager had been coached before, that is, an older manager tended to have more "coached" experience. 
In the case of the associate, time in career, time with company, and gender appeared to predict the length of a current coaching relationship. In addition, length of tenure and current coaching relationship as well as level of education reached appeared to predict whether an associate had been coached before. In other words, a male who has worked in a career and a company longer tended to have a longer current coaching relationship with his manager. However, a first-time relationship tended to exist for an associate with a lower level of education even when tenure and a longer current coaching relationship were in her/his favor. These intercorrelations appeared to describe who was coaching whom. Thus, organizational and coaching experiences such as these may prove to be important covariates in future investigations of the coaching process.

Exploring the data. Descriptive statistics were calculated for the response means for all scales in order to examine the quality and patterns of measurement responses. As seen in Table 4, neither extreme ranges nor range restrictions in the means or standard deviations are apparent. Then, sums of scale scores for all versions of the new scales were examined which indicate that both sample groups represented a normal distribution. When data for each scale were charted on a normal probability plot, case scores fell more or less on a straight line, and when charted on a detrended plot, they clustered around a horizontal line through zero. Also, Cronbach's alphas were calculated for all scales in order to investigate their respective reliabilities. The magnitude of these 
coefficient alphas are high for the new scales as seen in Table 5. This may be due to the fact that the number of scale items was high; there were 32 and 23 items in the coach and associate scales, respectively (see Appendixes B \& C).

\section{Examining the constructs. Because of minimal research on managerial} coaching practices and assessment, all scale data were explored in order to gain more insight into the coaching phenomenon. Intercorrelations were calculated for scales within each of the manager and associate survey forms in order to seek support for construct validity of the overall multi-domain research design. For the managers' scales, as seen in Table 6 , ten of fifteen pairs of the new and LMX scales are significantly and positively correlated at the $\underline{p}<.05$ level. However, the LPC scale is not significantly correlated with any of the other managers' ratings of coaching. For the associates' scales, as seen in Table 7, all pairs are significantly and positively correlated at the $\mathrm{p}<.05$ level. For both survey forms, the significant correlations were moderately high in magnitude. Although these correlations were not a test of construct validity, their frequency and size may suggest that the scales were measuring similar, yet not identical, constructs. Plus, they may indicate that the coaching domain scales were used to a similar extent by both the manager and associate groups in order to assess the coaching experience. This appears to be sufficient evidence to encourage further development and investigation of the three-domain coaching construct. 
Next, $\underline{t}$ tests were performed on various sets of mean responses on the Coach, Associate and LMX scales in order to compare the ratings and perspectives of coaching practices. First, differences in present and ideal scores were compared within each survey form. Secondly, differences in manager and associate perspectives of effective coaching were investigated. More specifically, the quality of relationship and leadership style were examined as predictors of the ratings of coaching as measured by the new coaching scales.

Present/Ideal ratings as independent variables. In order to investigate any differences in how the present and ideal scales were used, paired t tests were performed on each domain's set of matched present and ideal scales (see Appendixes B \& C). Per domain, present and ideal scale items were essentially the same questions, but the response anchors varied depending on the version. Response anchors for the Present Coach, Associate and LMX scales ranged from 1 (to not at all) to 5 (to a very great extent). In contrast, response anchors for the Ideal Coach, Associate and LMX scales the anchor responses ranged from 1 (not at all important) to 5 (very important).

Results of the paired $\underline{t}$ tests for both the manager and associate survey forms can be seen in Table 8 . As rated by managers, the ideal scale response means for all three coaching domains are greater and significantly different from their respective present scale response means. As rated by associates, the ideal scale response means for the coach and associate domains are greater and significantly 
different from their respective present scale response means. However, the ideal and present response means of the LMX scale are not significantly different from each other.

Finally, in order to examine differences in the manager and associate perspectives of coaching experiences, independent sample $\underline{t}$ tests were performed on sets of scale scores. This enabled an investigation of whether the quality of relationship and/or leadership style would predict coaching scale scores. First, in order to define the cutoff points for the low and high groupings, the median points for the LPC scale and each version of the LMX scales were calculated on the respective sums of score frequencies. The median point for the LPC scores for coaches was 62 which resulted in an equal split. In the managers' survey, where coaches rated present and ideal qualities of relationship, the median point for the Present LMX scores was 33. However, using this value as the cutoff point resulted in an unequal split. The split became more even when the cutoff point was adjusted to 34 . Likewise, the median point for the Ideal LMX scores for coaches was 36 which also produced an unequal split; when the cutoff point was adjusted to 37 , the split became more even. In the associates' survey, similar split issues existed for the Present and Ideal LMX scores. In both the present and ideal versions the median point was 36 . Consequently, 37 was used as the cutoff point which equalized the splits in both cases. 
Quality of relationship (LMX) as independent variable. As seen in Tables 9 and 10, for each of the Present and Ideal LMX scales, two levels of quality of relationship, as defined by median splits, were compared with each version of the Coach and Associate scale ratings. Result patterns differed for the manager and associate ratings. In both the Present and Ideal LMX scales, managers' ratings of coaching are not significantly different when high and low LMX groups were compared. In contrast, differences in associates' ratings of coaching were apparent when associates were split into high and low LMX groups for the Present and Ideal LMX scales. In the Ideal LMX scale, associate ratings for coaching are greater and significantly different when comparing high and low LMX groups for the Present Coach, Ideal Coach, and Ideal Associate scales. In the Present LMX scale, associate ratings for coaching are greater and significantly different for the Present Coach scale scores, but not for any of the other scale scores.

Leadership style (LPC) as independent variable. In order to investigate the impact of leadership style on coaching assessments, high and low LPC scores, or task and relationship-oriented styles, as determined by a median split, were compared by examining the coaching domain scale scores. For both the manager and associate forms, there are no significant differences between low 
and high LPC groupings among the Coach and Associate scale score. Likewise, when LPC scores were compared with the LMX scores, there are no significant differences. 


\section{Discussion}

Both qualitative and quantitative findings in this exploratory investigation have helped to illuminate important aspects of coaching beliefs, experiences and assessment. The qualitative inquiry helped to clarify the nature of coaching as experienced by the interview participants. Based on the content analysis of the interview data, important indicators of performance-based coaching were delineated and utilized to develop a survey for data collection and assessment. The quantitative investigation of three domains of coaching: coach, associate and quality of their relationship resulted in two major findings. First, statistical analyses demonstrated significant differences in how present and ideal scales for each domain were used such that ideal ratings were consistently higher than present ratings. Secondly, differences in the managers' and associates' coaching ratings were exhibited. Furthermore, for the associates, the quality of relationship between coach and associate appears to be a better predictor of coaching success than leadership style. Thus, support for continued use of these scales to study and/or improve coaching has been described.

\section{Interview/Content Analysis}

The content analysis helped address fundamental questions and issues about coaching according to the experiences and beliefs of a small group of managers and associates in the same work environment. This process also helped to define other important research questions for empirical investigation in the 
quantitative portion of the study. In spite of the complexity and ambiguity of managerial coaching, a distinct perception of coaching emerged from the interview discourse. However, descriptions of the coaching roles as well as the purpose and goals of coaching were not definitive. Due to time restraints of the participants, rather than conducting additional interviews, the researcher applied insights gained from previous research and meetings with the external coaching experts in order to further clarify these areas of coaching.

Limitations. The success of the qualitative inquiry was subject to both the accessibility and availability of the voluntary participants. First gaining entry into corporate environments and then obtaining cooperation from working professionals are challenging tasks. Allocating time for research participation is an additional responsibility that many individuals rightfully decline.

Consequently, I am grateful for those participants who were willing to contribute to this study. Yet, the small sample size and absence of paired coaching partners were perhaps the greatest liabilities of the qualitative component of this study.

The lack of a sole research sponsor and a specific coaching context had fundamental effects on the analyses. Overall, the levels of participation and commitment were lacking. Technically, results should have been presented to the interview participants and coaching experts for their final feedback. However, due to the time constraints and voluntary status of the participants, 
follow-up correspondence was limited. Therefore, decisions made about the number of interviews, number and breadth of gathered statements, and number of scale items were based on the judgment of the researcher.

Some researchers have asserted that coaching, leadership and management practices are either similar concepts or the same (see Evered \& Selman, 1989; Orth et al., 1987; Stowell, 1988). Investigations of such claims are ambitious tasks and beyond the scope of this study. However, insights from the content analysis have cast some support to such speculations.

Implication: Is coaching different from management? Since parallels have been drawn between coaching and managing, it seemed appropriate to pursue an alternative explanation of coaching in terms of management. The coach scale items were compared to Yukl's (Yukl \& Van Fleet, 1992) taxonomy of management practices. As seen in Appendix $\mathrm{N}$, each of the coaching items or statements corresponded to at least one of the categories of management. The extent to which the coaching and management practices appear parallel suggests that coaching may be a refined form of management, if not "essentially effective management. . ." as one direct report had expressed. To quote Evered and Selman $(1989 ;$ p.16), coaching may be "the heart of management".

Implication: Is coaching the same thing as leadership? Interview findings suggest that the coaching orientation under investigation was of a performance nature. As previously explained, the dimensionality of this form of coaching 
was defined in terms of "performance development" and "rapport building". Although these qualitative findings were not empirically tested, to the extent that they are analogous to the classic task and relationship dimensions, they offered a framework of coaching that can be explained in leadership terms.

However, two basic dimensions may not sufficiently explain and measure coaching. With regard to the task and relationship management constructs, Yukl and Van Fleet (1992) have argued that management is more than a two factor conceptualization. It may be wise to follow this reasoning in the continued development of coaching scales. In fact, the frameworks offered by the internal experts (see Appendix I) and the researcher (see Appendix D) provide evidence that a greater number of dimensions may be necessary in order to describe and assess coaching.

Even though a succinct description of coaching may appear desirable or practical, more comprehensive ways of structuring coaching need to be explored. Once again, leadership constructs may be useful in expanding coaching constructs. Because quality of relationship appeared to predict ratings of coaching, dimensions of LMX scales may offer alternative structuring for consideration. LMX constructs like trust, respect, mutual obligation (see Graen \& Uhl-Bien, 1995) or contribution, loyalty, affect, and professional respect (see Liden \& Maslyn, in press) are possible dimensions of coaching scales to explore. 


\section{Survey Study}

In this quantitative portion of the study, differences in how the managers and associates used the scales and how they based their perceptions of effective coaching were examined.

Differences in present/ideal ratings. Paired $\underline{t}$ tests of matched present and ideal response means demonstrated that overall, the two versions of the three domains of coaching were filled out differently by both groups of respondents. In other words, the present and ideal scale versions solicited different sets of responses that appear to have measured two different states of coaching. However, a rival explanation of these results may be due to the fact that the response anchors were different for the present and ideal versions (see Appendixes B \& C).

Differences in manager/associate ratings. Independent sample t tests demonstrated that for associates' ratings, for those in the high LMX group, scores on the coaching scales tend to be greater and often significantly different from those in the low LMX group. In contrast, no significant differences by quality of relationship were apparent for managers' ratings. However, in both groups it should be noted that all the non-significant differences were in the direction expected. Moreover, several showed promise of significance had the power of the test or sample size been greater. As it were, these findings suggested that associates tend to assess their coaching experiences based on their 
Managerial Coaching 55

perceived quality of relationship with the coach; coaches did not appear to assess their coaching experiences in this manner. In previous LMX research, managers/leaders tend to base assessments of their leader/member relationships on technical rather than social criteria (Sparrowe \& Liden, in press). The present findings appear consistent with this precedence. A lack of significant differences between both low and high quality of relationship among coaching assessments implies that, like managers, coaches may attribute successful coaching to something other than relationship criteria.

In addition, the managers' assessments of coaching were not found to be a function of their leadership style. This is also consistent with research findings that have illustrated that the LPC scale is a non-linear phenomenon. Fiedler's (1978) contingency theory states that a leadership style, task or relationshiporiented, is only successful a portion of the time depending on other conditions (i.e., task-oriented styles are successful with either high or low situational control and relationship oriented styles are successful with moderate control only). However, the present results could also be attributed to the manner in which the median scores were calculated. Median splits were determined on sample scores in order to equalize the groups of a small sample. This approach resulted in low and high groups where the latter was represented primarily by scores that would be equivalent to mid-range LPC scores according to Fiedler's 
Managerial Coaching 56

method of determining splits. Thus, the variance between task and relationshiporiented LPC scores calculated for the managers in this study was minimized.

In this study, if the high LPC group is in actuality a mid-level LPC group, the present results may have exhibited contrary evidence to an alternative view of the LPC dynamics. Kennedy (1982) believed that the mid-range of leadership style reflects a more neutral LPC position where leaders may be more effective because they can more easily adjust their style according to the situation at hand. According to this view, mid-range scores of managers should predict successful coaching. Yet, in this study, differences are not significant among managers' ratings of coaching when compared with the high or relationship-oriented leadership style group as defined by primarily mid-range LPC scores. Therefore, successful coaching may not be attributed to a neutral or more flexible leadership style where a manager is said to operate from a two-valueoriented leadership style.

Limitation: Sampling biases. Many of the limitations of this study revolve around sampling issues. To begin with, even though statistical significance was demonstrated on some critical aspects of coaching, increased sample size would increase the power of the tests performed. In addition, how well the survey participants from a wide variety of organizations and work cultures represented the targeted innovative technology and/or management population, is uncertain. The volunteers could have easily self-selected into a group of individuals who 
happen to share similar levels of interest and ideals regarding coaching practices. Their collective perspective may not be representative of a greater whole. Asserting that the present results reflect a universal view of coaching in innovative work environments would be presumptuous.

For different reasons, other sample biases may have occurred. For instance, inflated responses due to the self-reporting factor and/or simultaneous collection of measure responses (see Yukl et al., 10) may have confounded the test results. However, paired $\underline{t}$ tests performed on the present and ideal versions of the survey scales implied that response set or inflated rating effects were not apparent.

Limitation: Constructs. Investigations of construct validity and reliability were not subject to rigorous testing due to the small sample size. Nevertheless, Cronbach's alphas were computed in order to examine the internal consistency within each of the new scales. The resulting high reliability coefficients are to be expected for scales with a large number of items, as errors due to problematic statements may have been diffused. In other words, the 32 -item coach and 23-item associate scales may consist of dependable measures of coaching by default due to scale design, but this is not to say that they were necessarily unidimensional (see Cortina, 13). Furthermore, with regard to the three-domain construct, the similar patterns of scale intercorrelations exhibited 
by the two survey forms may attest to the credibility of the multi-domain measurement of coaching.

Limitation: Measurement bias. The fact that only associates appeared to base their perceptions of coaching on quality of relationship may be a reflection of measurement bias. In this study, due to the extent of participant availability, paired coaching partners were not consulted during the interview stage and matched coach/coachee responses were not a prerequisite of participating in the survey. In addition, an associate reported on a specific coach, whereas coaches reported in terms of a general coaching relationship. In other words, the coach likely imagined a composite rather than a specific relationship. In order to investigate a true one-on-one relationship, future research needs to be conducted on matched dyadic responses.

Limitation: Scaling bias. The variation between the present and ideal response anchors (see Appendixes B \& C) may have confounded the attempt to compare the same phenomena from two different frames of mind. Further examination of the effects of identical versus similar response anchors is needed in order to address the limitations or benefits of this approach.

Limitation: Research design. A multi-rater and multi-domain study is not a foolproof method of assessing coaching. Although this approach may be a more comprehensive investigation of coaching, the three fundamental domains are only a part of a greater phenomenon. Because performance coaching is both an 
interactive and developmental relationship, there are relationship processes and stages which may impact the effectiveness of coaching. Plus, the context in which coaching occurs may influence the success of coaching according to environmental variables. Furthermore, links to other measured outcomes are needed in order to demonstrate the benefits of successful coaching such as job satisfaction from the associates' perspective or the associates' performance improvement as assessed by the coach. Therefore, investigations of coaching programs must examine multi-dimensional factors in order to thoroughly understand what makes for successful coaching.

Nevertheless, the present findings have contributed to the theoretical and empirical understanding of coaching. A content analysis of the interviews resulted in a preliminary description of performance coaching which was used to develop scales for an empirical investigation of coaching. On one hand, these scales enabled analyses which produced significant results. On the other hand, they were not subject to a factor analysis or stringent tests of validity and reliability. However, to the extent that each survey form exhibited a majority of significant scale intercorrelations and that the two sets of intercorrelations exhibited similar patterns, the multi-domain scales have demonstrated a reasonable degree of credibility. In addition, paired $\underline{t}$ tests helped to demonstrate that the present and ideal scales were used substantially different. This difference in actual and desired coaching experiences may help to delineate 
Managerial Coaching 60

areas in which coaching can be improved. Finally, independent sample t tests helped to demonstrate differences in managers' and associates' perspectives of effective coaching. The two unique perceptions of coaching success exhibited may lead to a need for further one-on-one training and development for both the coach and associate. Fundamentally, these dual-perspective results mirrored leadership studies where differences in managers' and subordinates' perceptions of leadership tend to be anchored in task and relationship values, respectively.

Implication: Survey design. Although, social desirability may be suspect in cases of self-reports, results of the paired $t$ tests rendered a possible solution to such response biases. Significant differences in how present and ideal scales were used has demonstrated that single-rater/multi-version assessments of performance coaching may serve as an inherent mechanism to ensure against response sets or inflated ratings. Likewise, these differences may be the best argument against restricted ranges or ceiling effects.

Implication: Alternative application. Further study and use of this assessment tool has been supported by the research results. Alternative application of this tool might be considered for research in order to benefit coaching dyads more directly. Ideally, this multi-domain survey could serve as a two-way communication tool for a single unit or coaching dyad in order to exchange and assess one-on-one feedback. If coaching is a mutual phenomenon and equivalent to effective management, then a dual-rater coaching assessment 
tool may be critical. This tool could also lend itself to a 360 degree review process study design in order to examine collective feedback from multiple associates about a single coach. Typically, such management tools include two or three items at the most about coaching. When performance coaching is a corporate initiative, a coaching-oriented review process tool that examines a greater number of coaching practices, behaviors and attributes would be more appropriate.

Implication: Links to leadership theories and constructs. The greater part of this study of coaching was centered on links between coaching and leadership. Leadership theory, constructs and aspects contributed to the research design and questions. To begin with, the multi-domain research design, modeled after the leader/member relationship prototype, helped to anchor the coaching relationship in fundamental perspectives like social exchange or role theories. Likewise, parallels drawn between the basic functions of leadership and coaching helped to ground coaching constructs in more definitive terms and dimensionality. Although the validity of task and relationship-like dimensions of coaching was not tested, a division between task and relationship-oriented perspectives of coaching was exhibited. Specifically, differences in how managers and associates perceived effective coaching appeared rooted in task and relationship orientations which supports the assertion that coaching and leadership are the same phenomenon. 
Implication: Who benefits from coaching? The demographic correlations have shed some light on who coaches whom as well as the utility of coaching according to the research participants. Managers more experienced in their respective companies and job positions appeared to have a longer current coaching relationship with an associate. Plus, older managers who coached tended to have been coached before. Therefore, a more traditional, senior figure or hierarchical coach was the apparent profile projected in this survey sample of managers. Likewise, the projected associate profile appeared to reflect characteristics of a more traditional, vertical form of relationship. An associate, more often a male, with more experience in a career and company tended to have a longer coaching relationship. However, an associate with more tenure, longer current coaching relationships, but less education tended to be in a first-time coaching relationship. Therefore, an incumbent versus new employee and a male verses female tended to have a longer current coaching relationship. These patterns reflect earlier traditions of developmental relationships like coaching where select male managers who showed promise were prepared by their supervisors for advancement within the company (Shapiro, Haseltine \& Rowe, 178).

Based on these observations, it is possible that coaching relationships are not as accessible and equitable as the literature might lead us to believe. In more dynamic and equitable work environments where coaching relationships are 
believed to be more mutual and horizontal, one might anticipate that both younger and older managers would be coaching others based on their expertise rather than duration of employment with the company. Likewise, in environments where coaching is believed to be a pervasive phenomenon that breeds leadership across the workforce, similar numbers of newer and incumbent employees would be engaged in coaching relationships. Plus, male and female associates would be maintaining similar durations of coaching relationships. Contrary to these expectations the significant correlations suggest that the utility of coaching as a mechanism for equalizing, inspiring and empowering workers, may be more ideal than real. In fact, when coaching practices remain implicit and ambiguous, relationships may tend to evolve according to more traditional customs at the risk of perpetuating age and gender biases.

Concluding remarks. This exploratory research on managerial coaching has resulted in a better understanding of what performance coaching looks like for a small sample of managers and associates in environments where technology and management practices are innovative. In spite of the more implicit nature of coaching, there was apparent agreement among the interview and survey samples on the actual and desired coaching experiences. Likewise, these two small segments of the work world also reflected much of the spirit of coaching that has been addressed in the research literature. 
In essence, coaching is about relationships. Specifically, performance coaching is about a significant work relationship in which a manager and associate are partners in their mutual development and success. A content analysis helped to describe the basic functions of coaching as "performance development" and "rapport building", dimensions kindred to the classic task and relationship orientations of leadership. Yet, limiting the structure of such a complex phenomenon to two dimensions may result in constructs that are too narrowly defined. Nevertheless, a substantial division of task and relationshiporiented values between the managers and associates was apparent in their contrasting perceptions of what makes for successful coaching. In Stowell's (1988) words, "the support [relationship-oriented] behaviors were the centerpiece of coaching . . ." for the associates who based their assessment of coaching on the quality of relationship with the coach. In contrast, managers did not attribute successful coaching to the quality of their coaching relationships. These findings suggest that different sets of assumptions and motivations exist for coaches and associates as they tend to exist for leaders and members in other important work relationships. Moreover, these findings support subsequent research in order to better understand, acknowledge and value these differences. 
Table 1

Means and Ranges of Managers' and Associates' Demographics

\begin{tabular}{|c|c|c|c|c|}
\hline & $\begin{array}{l}\text { MANAGER } \\
\underline{n=13}\end{array}$ & & $\begin{array}{l}\text { ASSOCIAT } \\
\underline{n}=19\end{array}$ & \\
\hline Demographic & $\underline{\text { Mean }}$ & $\underline{\text { Range }}$ & $\underline{\text { Mean }}$ & $\underline{\text { Range }}$ \\
\hline \multicolumn{5}{|l|}{ Age of participant } \\
\hline & $42 y$ & $33-59 y$ & $39 y$ & $30-58 y$ \\
\hline $\begin{array}{l}\text { Highest level of } \\
\text { education }{ }^{2}\end{array}$ & 3.3 & 2 & 2.7 & 3 \\
\hline Time in career & $11 \mathrm{y} / 7 \mathrm{~m}$ & $1^{1 / 2}-24 y$ & $7 y / 6 m$ & $1-24 y$ \\
\hline $\begin{array}{l}\text { Tenure with } \\
\text { company }\end{array}$ & $5 \mathrm{y} / 4 \mathrm{~m}$ & $8 m-20 y / 6 m$ & $7 \mathrm{y} / 10 \mathrm{~m}$ & $7 m-24 y / 6 m$ \\
\hline $\begin{array}{l}\text { Time in present } \\
\text { position }\end{array}$ & $2 y$ & $4 m-10 y$ & $3 y / 3 m$ & $10 \mathrm{~m}-5 \mathrm{y} / 10 \mathrm{~m}$ \\
\hline $\begin{array}{l}\text { Time in main } \\
\text { group }\end{array}$ & $3 y / 11^{1 / 2} \mathrm{~m}$ & $8 m-16 y / 4 m$ & $3 y / 9 m$ & $8 m-6 y / 2 m$ \\
\hline $\begin{array}{l}\text { Level of } \\
\text { management }\end{array}$ & 2 & 2 & N/A & N/A \\
\hline Span of control & 9 assc. & $0-30$ assc. & N/A & N/A \\
\hline $\begin{array}{l}\text { Current coaching } \\
\text { relationships }\end{array}$ & 6 assc. & $0-15^{\mathrm{c}}$ assc. & N/A & N/A \\
\hline $\begin{array}{l}\text { Longest coaching } \\
\text { relationship }\end{array}$ & $1^{3 / 4} y$ & $0-8 y$ & $2 y$ & $2 \mathrm{~m}-3 \mathrm{y} / 10 \mathrm{~m}$ \\
\hline
\end{tabular}

Note. $y=$ years; $m=$ months

${ }^{a}$ Levels of education were defined as: $1=$ high school, $2=$ some college, $3=\mathrm{BA} / \mathrm{BS}, 4=$ Masters, and $5=$ Doctorate

${ }^{\mathrm{b}}$ Management levels were defined as: $1=$ lower, 2 =middle, and =upper

${ }^{c}$ One of the survey respondents was a manager interviewed earlier in the study when coaching associates and since has been reassigned to an independent contributor position which explains the minimum ratings of 0 in some of the demographic variables. 
Table 2

Intercorrelations Among Important Organizational and Coaching Demographics of Managers

\begin{tabular}{|c|c|c|c|c|c|c|c|c|c|c|c|c|}
\hline Demographic & 1 & 2 & 3 & 4 & 5 & 6 & 7 & 8 & 9 & 10 & 11 & 12 \\
\hline \multicolumn{13}{|l|}{ 1. Gender } \\
\hline 2. Age & .16 & & & & & & & & & & & \\
\hline 3. Caretime & -.13 & .07 & & & & & & & & & & \\
\hline 4. Tenure & -.17 & .23 & -.34 & & & & & & & & & \\
\hline 5. Grptime & .16 & -.17 & .41 & .17 & & & & & & & & \\
\hline 6. Curtime & -.17 & .28 & .09 & $.75^{*}$ & .31 & & & & & & & \\
\hline 7. Educ & -.46 & -.08 & .25 & -.33 & -.45 & -.16 & & & & & & \\
\hline 8. Level & .14 & .18 & .48 & .07 & .22 & .10 & .05 & & & & & \\
\hline 9. Span & .09 & -.24 & .52 & -.18 & $.86^{*}$ & .10 & -.10 & .17 & & & & \\
\hline 10. RItships & .01 & -.41 & .21 & .15 & .23 & .13 & .42 & .21 & .26 & & & \\
\hline 11. Presterm & .03 & .09 & .03 & $.72^{*}$ & .18 & $.81^{*}$ & -.06 & .28 & -.06 & .43 & & \\
\hline 12. Beencoac & -.27 & $-.72^{*}$ & .29 & -.24 & .18 & .09 & .12 & -.04 & .29 & .29 & .06 & \\
\hline
\end{tabular}

Note. For Gender; $0=$ male, $1=$ female. Caretime $=$ the time accrued in present career track.

Tenure $=$ the length of time employed with present company. Grptime $=$ the length of time in main group or function of the type of work. Curtime $=$ the length of time in the current job position.

$E d u c=$ the highest level of education reached; $1=$ high school, $2=$ some college, $3=\mathrm{BA} / \mathrm{BS}$, 4=Masters, and 5=Doctorate. Level=level of management; $1=$ lower, $2=$ middle, and $3=$ upper. Span $=$ span of control. Rltships $=$ the number of coaching relationships among a manager's span of control. Presterm $=$ the longest term of a manager's present coaching relationships.

Beencoac $=$ have been coached by a manager before; $1=$ yes, $2=$ no.

${ }^{*} \mathrm{p}<.05$ 


\section{Table 3}

$\underline{\text { Intercorrelations Among Important Organizational and Coaching Demographics }}$

\section{of Associates}

\begin{tabular}{|c|c|c|c|c|c|c|c|c|c|c|}
\hline Demographic & 1 & 2 & 3 & 4 & 5 & 6 & 7 & 8 & 9 & 10 \\
\hline \multicolumn{11}{|l|}{ 1. Gender } \\
\hline 2. Age & -.16 & & & & & & & & & \\
\hline 3. Caretime & -.01 & $.68^{*}$ & & & & & & & & \\
\hline 4. Tenure & -.28 & .10 & -.18 & & & & & & & \\
\hline 5. Grptime & -.09 & -.00 & .46 & .18 & & & & & & \\
\hline 6. Curtime & -.06 & .12 & .42 & .20 & $.47^{*}$ & & & & & \\
\hline 7. Educ & -.06 & -.19 & .10 & -.37 & -.10 & .13 & & & & \\
\hline 8. Curterm & $-.50^{*}$ & .34 & $.50^{*}$ & $.56^{*}$ & .33 & .31 & -.04 & & & \\
\hline 9. Shipbef & -.16 & -.09 & -.16 & $.53^{*}$ & -.07 & -.02 & $-.47 *$ & $.50^{*}$ & & \\
\hline 10. Subship & .34 & -.10 & -.18 & -.40 & -.15 & -.35 & .00 & -.31 & .00 & \\
\hline
\end{tabular}

Note. For Gender; $0=$ male, $1=$ female. Caretime $=$ time accrued in present career track.

Tenure $=$ the length of time employed with present company. Grptime $=$ the length of time in main group or function of type of work. Curtime= the length of time in the current job position.

$E d u c=$ the highest level of education reached; $1=$ high school, $2=$ some college, $3=\mathrm{BA} / \mathrm{BS}$, $4=$ Masters, and 5=Doctorate. Curterm $=$ the length of an associate's current coaching relationship with a manager. Shipbef $=$ have been coached by a manager before; $1=y e s, 2=$ no. Subship $=$ have coached a subordinate before; $1=$ yes, $2=$ no.

${ }^{*} \mathrm{p}<.05$ 
Managerial Coaching 68

Table 4

Scale Descriptive Statistics for Mean Item Responses

\begin{tabular}{llllllll}
\hline & \multicolumn{2}{l}{ MANAGER } & & \multicolumn{2}{l}{ ASSOCIATE } & \\
$\underline{\text { Scale }}$ & $\underline{\mathrm{n}}$ & $\underline{\mathrm{M}}$ & $\underline{\mathrm{SD}}$ & $\underline{\mathrm{n}}$ & $\underline{\mathrm{M}}$ & $\underline{\mathrm{SD}}$ \\
\hline 1. Present Coach & 13 & 4.0 & .4 & 19 & 3.8 & .8 \\
2. Ideal Coach & 13 & 4.5 & .3 & 19 & 4.3 & .4 \\
3. Present Associate & 13 & 3.8 & .7 & 19 & 4.0 & .5 \\
4. Ideal Associate & 13 & 4.5 & .5 & 19 & 4.5 & .3 \\
5. Present LMX & 12 & 4.2 & .5 & 19 & 4.3 & .9 \\
6. Ideal LMX & 12 & 4.5 & .4 & 19 & 4.5 & .5 \\
7. LPC & 12 & 3.9 & 1.0 & N/A & N/A & N/A \\
\hline
\end{tabular}


Table 5

Cronbach's Alpha Reliability Coefficients for Scales

\begin{tabular}{llllll}
\hline & \multicolumn{2}{l}{ MANAGER } & \multicolumn{2}{l}{ ASSOCLATE } \\
Scale & $\underline{\mathrm{n}}$ & $\underline{\text { alpha }}$ & $\underline{\mathrm{n}}$ & $\underline{\text { alpha }}$ \\
\hline Present Coach & 11 & .91 & 14 & .98 \\
Ideal Coach & 10 & .92 & 16 & .94 \\
Present Associate & 13 & .96 & 14 & .90 \\
Ideal Associate & 13 & .94 & 13 & .90 \\
Present LMX & 12 & .70 & 19 & .97 \\
Ideal LMX & 12 & .69 & 19 & .90 \\
LPC & 11 & .86 & N/A & N/A \\
\hline
\end{tabular}


Table 6

Manager Survey: Intercorrelations Among New and Previous Scales

\begin{tabular}{llllllll}
\hline Scale & 1 & 2 & 3 & 4 & 5 & 6 & 7 \\
\hline 1. Present Coach & & & & & & \\
2. Ideal Coach & $.61^{*}$ & & & & & \\
3. Present Associate & $.72^{*}$ & $.70^{*}$ & & & & \\
4. Ideal Associate & .35 & $.77^{*}$ & $.60^{*}$ & & & \\
5. Present LMX & .54 & $.65^{*}$ & $.73^{*}$ & $.69^{*}$ & & \\
6. Ideal LMX & .40 & $.68^{*}$ & .41 & .53 & $.74^{*}$ & \\
7. LPC & .05 & .25 & .30 & .41 & .35 & .51 \\
\hline
\end{tabular}

$* \mathrm{p}<.05$

Table 7

Associate Survey: Intercorrelations Among New and Previous Scales

\begin{tabular}{lllllll}
\hline$\underline{\text { Scale }}$ & 1 & 2 & 3 & 4 & 5 & 6 \\
\hline 1. Present Coach & & & & & \\
2. Ideal Coach & $.59^{*}$ & & & & \\
3. Present Associate & $.69 *$ & $.48^{*}$ & & & \\
4. Ideal Associate & $.77^{*}$ & $.66^{*}$ & $.92^{*}$ & & \\
5. Present LMX & $.90^{*}$ & $.53^{*}$ & $.58^{*}$ & $.61^{*}$ & \\
6. Ideal LMX & $.74^{*}$ & $.70^{*}$ & $.52^{*}$ & $.64^{*}$ & $.79 *$ \\
\hline
\end{tabular}

${ }^{*} \mathrm{p}<.05$ 
Table 8

\section{Paired t-tests: Mean Differences of Mean Scores of Matched Present and Ideal Scales}

\begin{tabular}{|c|c|c|c|c|c|c|c|c|c|c|}
\hline \multirow[b]{2}{*}{ Matched Scales } & \multicolumn{5}{|c|}{ MANAGER } & \multicolumn{5}{|c|}{ ASSOCIATE } \\
\hline & $\frac{\mathrm{M} \text { of }}{\underline{\mathrm{I}} \mathrm{P}}$ & $\underline{\mathrm{M}}$ & $\underline{\mathrm{SD}}$ & 1 & $\underline{\mathrm{df}}$ & $\frac{M \text { of }}{\underline{\text { I/P }}}$ & $\underline{\underline{M}}$ & $\underline{\mathrm{SD}}$ & $\underline{t}$ & $\underline{\mathrm{df}}$ \\
\hline Ideal Coach & I 4.5 & & & & & I 4.3 & & & & \\
\hline Present Coach & P 4.0 & 0.5 & 0.3 & $5.59^{*}$ & 12 & P 3.8 & 0.6 & 0.7 & $3.85^{*}$ & 18 \\
\hline Ideal Associate & I 4.5 & & & & & I 4.5 & & & & \\
\hline Present Associate & P 3.8 & 0.7 & 0.6 & $4.26^{*}$ & 12 & P 4.0 & 0.5 & 0.4 & $5.38^{*}$ & 18 \\
\hline Ideal LMX & I 4.5 & & & & & I 4.5 & & & & \\
\hline Present LMX & P 4.2 & 0.3 & 0.3 & $3.43^{*}$ & 11 & P 4.3 & 0.2 & 0.6 & 1.63 & 18 \\
\hline
\end{tabular}

Note. $I=$ ideal scale mean score; $\mathrm{P}=$ present scale mean score; $\mathbf{M}$ Diff $=$ mean difference between ideal and present mean scores. Response anchors for ideal scales were: 1 (not at all important), 2 (somewhat unimportant), 3 (neither unimportant nor important), 4 (somewhat important), and 5 (very important). Response anchors for present scales were: 1 ( not at all), 2 (to a limited extent), 3 (to a moderate extent), 4 (to a considerable extent), and 5 (to a very great extent).

${ }^{*} \mathrm{p}<.05$ 
Table 9

Independent Sample t-tests with Managers' LMX Low/High Quality of Relationship Groupings and Coaching Ratings

\begin{tabular}{|c|c|c|c|c|c|c|c|c|c|c|c|c|}
\hline & \multicolumn{6}{|c|}{ PRESENT LMX } & \multicolumn{6}{|c|}{ IDEAL LMX } \\
\hline & $\begin{array}{l}\mathrm{H} / \mathrm{L} \\
\text { Group } \underline{\mathrm{M}}\end{array}$ & $\begin{array}{l}\mathrm{H} / \mathrm{L} \\
\text { Group SD }\end{array}$ & $\underline{\mathrm{M}}$ & 1 & df & 2-Tail Sig & $\begin{array}{l}\mathrm{H} / \mathrm{L} \\
\text { Group } \underline{\mathrm{M}}\end{array}$ & $\begin{array}{l}\mathrm{H} / \mathrm{L} \\
\text { Group } \underline{\mathrm{SD}}\end{array}$ & $\underline{\mathbf{M}}$ Diff & 1 & df & 2-Tail Sig \\
\hline MANAGER & & & & & & & & & & & & \\
\hline $\begin{array}{l}\text { Present } \\
\text { Coach }\end{array}$ & $\begin{array}{l}\text { H } 133.8 \\
\text { L } 124.1\end{array}$ & $\begin{array}{l}\text { H } 13.5 \\
\text { L } 10.6\end{array}$ & 9.7 & 1.45 & 11 & .175 & $\begin{array}{l}\text { H } 128.8 \\
\text { L } 126.9\end{array}$ & $\begin{array}{l}\text { H } 14.5 \\
\text { L } 12.2\end{array}$ & 1.9 & .25 & 10 & .806 \\
\hline $\begin{array}{l}\text { Ideal } \\
\text { Coach }\end{array}$ & $\begin{array}{l}\text { H } 147.5 \\
\text { L } 140.7\end{array}$ & $\begin{array}{l}\text { H } 6.5 \\
\text { L } 10.7\end{array}$ & 6.8 & 1.35 & 11 & .203 & $\begin{array}{l}\text { H } 147.0 \\
\text { L } 139.3\end{array}$ & $\begin{array}{l}\text { H } 7.1 \\
\text { L } 8.0\end{array}$ & 7.7 & 1.72 & 10 & .116 \\
\hline $\begin{array}{l}\text { Present } \\
\text { Associate }\end{array}$ & $\begin{array}{l}\text { H } 95.0 \\
\text { L } 80.0\end{array}$ & $\begin{array}{l}\text { H } 11.3 \\
\text { L } 17.6\end{array}$ & 15.0 & 1.79 & 11 & .101 & $\begin{array}{ll}\text { H } & 90.2 \\
\text { L } & 81.9\end{array}$ & $\begin{array}{l}\text { H } 9.9 \\
\text { L } 19.3\end{array}$ & 8.3 & .88 & 10 & .400 \\
\hline $\begin{array}{l}\text { Ideal } \\
\text { Associate }\end{array}$ & $\begin{array}{l}\text { H } 108.2 \\
\text { L } 97.7\end{array}$ & $\begin{array}{l}\text { H } 6.6 \\
\text { L } 12.1\end{array}$ & 10.5 & 1.88 & 11 & .087 & $\begin{array}{l}\text { H } 105.6 \\
\text { L } 98.6\end{array}$ & $\begin{array}{lr}\text { H } & 5.9 \\
\text { L } 13.0\end{array}$ & 7.0 & 1.12 & 10 & .287 \\
\hline
\end{tabular}

Note. $\mathrm{L}=$ low quality of relationship; $\mathrm{H}=$ high quality of relationship.

${ }^{*} \mathrm{p}<.05$ 
Table 10

Independent Sample t-tests with Associates' LMX Low/High Quality of Relationship Groupings and Coaching Ratings

\begin{tabular}{|c|c|c|c|c|c|c|c|c|c|c|c|c|}
\hline & \multicolumn{6}{|c|}{ PRESENT LMX } & \multicolumn{6}{|c|}{ IDEAL LMX } \\
\hline & $\begin{array}{l}\mathrm{H} / \mathrm{L} \\
\text { Group } \underline{\mathrm{M}}\end{array}$ & $\begin{array}{l}\mathrm{H} / \mathrm{L} \\
\text { Group SD }\end{array}$ & $\frac{M}{\text { Diff }}$ & $\mathbf{t}$ & $\underline{\mathrm{df}}$ & 2-Tail Sig & $\begin{array}{l}\mathbf{H} / \mathbf{L} \\
\text { Group } \underline{M}\end{array}$ & $\begin{array}{l}\mathrm{H} / \mathrm{L} \\
\text { Group SD }\end{array}$ & $\underline{M}$ Diff & 1 & df & 2-Tail Sig \\
\hline \multicolumn{13}{|c|}{ ASSOCIATE } \\
\hline $\begin{array}{l}\text { Present } \\
\text { Coach }\end{array}$ & $\begin{array}{l}\text { H } 131.9 \\
\text { L } 106.2\end{array}$ & $\begin{array}{l}\text { H } 15.5 \\
\text { L } 25.1\end{array}$ & 25.7 & 2.64 & 17 & $.017^{*}$ & $\begin{array}{l}\text { H } 131.7 \\
\text { L } 106.4\end{array}$ & $\begin{array}{l}\text { H } 14.8 \\
\text { L } 25.8\end{array}$ & 25.3 & 2.58 & 17 & $.019 *$ \\
\hline $\begin{array}{l}\text { Ideal } \\
\text { Coach }\end{array}$ & $\begin{array}{l}\text { H } 140.6 \\
\text { L } 134.9\end{array}$ & $\begin{array}{l}\text { H } 12.7 \\
\text { L } 15.3\end{array}$ & 5.7 & .87 & 17 & .395 & $\begin{array}{l}\text { H } 146.7 \\
\text { L } 129.4\end{array}$ & $\begin{array}{l}\text { H } 7.4 \\
\text { L } 13.7\end{array}$ & 17.3 & 3.36 & 17 & $.004^{*}$ \\
\hline $\begin{array}{l}\text { Present } \\
\text { Associate }\end{array}$ & $\begin{array}{l}\text { H } 91.9 \\
\text { L } 85.3\end{array}$ & $\begin{array}{l}\text { H } 18.7 \\
\text { L } 17.1\end{array}$ & 6.6 & .80 & 17 & .433 & $\begin{array}{l}\text { H } 94.9 \\
\text { L } 82.6\end{array}$ & $\begin{array}{l}\text { H } 7.6 \\
\text { L } 22.2\end{array}$ & 12.3 & 1.57 & 17 & .134 \\
\hline $\begin{array}{l}\text { Ideal } \\
\text { Associate }\end{array}$ & $\begin{array}{l}\text { H } 100.6 \\
\text { L } 95.7\end{array}$ & $\begin{array}{l}\text { H } 14.4 \\
\text { L } 15.3\end{array}$ & 4.9 & .71 & 17 & .488 & $\begin{array}{l}\text { H } 106.1 \\
\text { L } 90.7\end{array}$ & $\begin{array}{l}\text { H } 6.3 \\
\text { L } 16.5\end{array}$ & 15.4 & 2.63 & 17 & $.017^{*}$ \\
\hline
\end{tabular}

Note. $L=$ low quality of relationship; $\mathrm{H}=$ high quality of relationship.

$*_{\mathrm{g}}<.05$ 


\section{References}

Allenbaugh, G. E. (1983, May). Coaching: A management tool for a more effective rrk performance. Management Review, 21-26.

Allenbaugh, G. E. (1994, Nov). Performance coaching: Empowering others to be eir best. (Available from Allenbaugh Associates Inc., 17545 Kelok Road, Lake Oswego, regon 97034).

Bass, B. M. (1990). Bass \& Stogdill's handbook of leadership (3rd ed.). New York: he Free Press.

Bauer, T. N. \& Green, S. G. (1996). Development of leader-member exchange: A sngitudinal test. Academy of Management Journal, 39, 1538-1567.

Cortina, J. M. (1993). What is coefficient alpha? An examination of theory and pplications. Journal of Applied Psychology, 78, 98-104.

Evered, R. D. \& Selman, J. C. (1989). Coaching and the art of management. Organizational Dynamics, $18,16-32$.

Fiedler, F. E. (1978). The contingency model and the dynamics of the leadership Jrocess. In L. Berkowitz (Ed.), Advances in experimental social psychology (pp. 59-112). New York: Academic Press.

Fleishman, E. A. \& Peters, D. R. (1962). Interpersonal values, leadership attitudes and managerial success. Personnel Psychology, 15, 127-143.

Frost, D. E. (1993). Course: Leadership \& Group Effectiveness. Portland State University. (Spring).

Graen, G. B. \& Uhl-Bien, M. (1995). Development of leader-member exchange (LMX) theory of leadership over 25 years: Applying a multi-level multi-domain perspective. Leadership Quarterly, 6, 219-247.

Graham, S. W., Wedman, J. F. \& Garvin-Kester, B. (1993). Manager coaching skills: Development and application. Performance Improvement Quarterly, 6, 2-13.

Graham, S., Wedman, J. F. \& Garvin-Kester, B. (1994). Manager coaching skills: What makes a good coach? Performance Improvement Quarterly, 7, 81-94.

Kennedy, J. K., Jr. (1982). Middle LPC leaders and the contingency model of leadership effectiveness. Organizational Behavior and Human Performance, 30, 1-14. 
Liden, R. C. \& Maslyn, J. M. (in press). Multidimensionality of leader-member hange: An empirical assessment through scale development. Journal of Management.

Lincoln, Y. S. \& Guba, E. G. (1985). Naturalistic inquiry. Newbury Park, CA: ge.

Lofland, J. \& Lofland, L. H. (1995). Analyzing social settings: A guide to qualitative servation and analysis (3rd ed.). Belmont, CA: Wadsworth.

Marshall, C. \& Rossman, G. B. (1995). Designing qualitative research (2nd. ed.). llifornia: Sage Publications, Inc.

McKenzie, B. (1989). Peak performance through counseling, coaching, and mentoring iesearch report No. 44-89-E). Ontario: The Conference Board of Canada, Human Resource evelopment Centre.

Orth, C. D., Wilkinson, H. E., \& Benfari, R. C. (1987). The manager's role as Jach and mentor. Organizational Dynamics, 15, 64-74.

Scandura, T. A. \& Graen, G. B. (1984). Moderating effects of initial leader-member xchange status on the effects of a leadership intervention. Journal of Applied Psychology. ig. 428-436.

Scandura, T. A., Graen, G. B., \& Novak, M. A. (1986). When managers decide not o decide autocratically: An investigation of leader-member exchange and decision influence. lournal of Applied Psychology, 71, 579-584.

Schelling, C. R. (1991). Measuring the impact of training, Cincinnati: AT\&T Research Report

Schriesheim, C. A. \& Kerr, S. (1974). Psychometric properties of the Ohio State Leadership scales. Psychological Bulletin, 81, 756-765.

Shapiro, E. C., Haseltine, F. P. \& Rowe, M. P. (1978, Spring). Moving up: Role models, mentors, and the "patron system". Sloan Management Review, 51-58.

Strauss, A. \& Corbin, J. (1990). Basics of qualitataive research: Grounded theory procedures and techniques. Newbury Park, CA: Sage.

Stowell, S. J. (1988, June). Coaching: A commitment to leadership. Training \& Development Journal, 42, 34-38.

Sparrowe, R. T. \& Liden, R.C. (in press). Process and structure in leader-member exchange. Academy of Management Review. 
Vecchio, R. P. (1987). Situational leadership theory: An examination of a prescriptive ory. Journal of Applied Psychology, 72, 444-451.

Yukl, G. P \& Van Fleet, D. D. (1992). Theory and research on leadership in zanizations. In M. D. Dunnette \& L. M. Hough (Eds.), Handbook of industrial and zanizational psychology (pp 147-197). Palo Alto, California: Consulting Psychologist ess.

Yukl, G. P., Wall, S. \& Lepsinger, R. (1990). Preliminary report on the validation the MPS. In K.E. Clark \& M.B. Clark (Eds.), Measures of leadership.

Yukl, G., Wall, S. \& Lepsinger, R. (1990). Preliminary report on validation of the anagerial practices survey. In K. Clark \& M. Clark (Eds.), Measures of leadership (pp. 23-238). West Orange, NJ: Leadership Library of America. 
APPENDIX A

THE PRIMARY FUNCTIONS OF MANAGERIAL LEADERSHIP AND

COACHING 


\section{The Primary Functions of Managerial Leadership and Coaching}

\begin{tabular}{|c|c|c|}
\hline $\begin{array}{l}\text { MANAGERIAL LEADERSHIP } \\
\text { Fleishman \& Peters (1962) }\end{array}$ & $\begin{array}{c}\text { MANAGERIAL COACHING } \\
\text { Stowell (1988) }\end{array}$ & $\begin{array}{l}\text { MANAGERIAL COACHING } \\
\text { Schelling (1991) }\end{array}$ \\
\hline $\begin{array}{c}\text { Initiating Structure } \\
\text { task performance \& completion } \\
\text { task, technology, business }\end{array}$ & Initiating Behaviors & Performance-Oriented \\
\hline & $\begin{array}{l}\text { feedback \& analysis of issues and } \\
\text { concerns }\end{array}$ & $\begin{array}{l}\text { provide regular performance } \\
\text { feedback }\end{array}$ \\
\hline goal clarification & $\begin{array}{l}\text { clarification of leader expectations } \\
\text { and requirements }\end{array}$ & communicate clear performance \\
\hline protection for subordinate & $\begin{array}{l}\text { exploration of impact and effects of } \\
\text { employee's actions }\end{array}$ & $\begin{array}{l}\text { consider all relevant information } \\
\text { when appraising performance }\end{array}$ \\
\hline structure for attaining task goals & $\begin{array}{l}\text { initiate action planning around } \\
\text { solutions and desired changes }\end{array}$ & observe with clients \\
\hline $\begin{array}{l}\text { initiation of challenging } \\
\text { assignments }\end{array}$ & $\begin{array}{l}\text { seeking commitment to the action } \\
\text { plan }\end{array}$ & \\
\hline role definition & $\begin{array}{l}\text { clarification of }+\& \text { - consequences } \\
\text { connected to future action and plans }\end{array}$ & $\begin{array}{l}\text { recognize and reward high } \\
\text { performance }\end{array}$ \\
\hline $\begin{array}{c}\text { Consideration } \\
\text { group cohesion \& maintenance } \\
\text { relationship, social, human } \\
\end{array}$ & Supportive Behaviors & Relationship-Oriented \\
\hline role model & $\begin{array}{l}\text { collaboration regarding solutions to } \\
\text { the problem }\end{array}$ & $\begin{array}{l}\text { know the staff well enough to help } \\
\text { them develop self-improvement } \\
\text { plans }\end{array}$ \\
\hline develop mutual trust $\&$ respect & $\begin{array}{l}\text { acceptance of some responsibility } \\
\text { for the situation }\end{array}$ & $\begin{array}{l}\text { provide help, training, and } \\
\text { guidance }\end{array}$ \\
\hline & $\begin{array}{l}\text { provisions of help and assistance, } \\
\text { e.g., training \& resources }\end{array}$ & \\
\hline display empathy \& connection & $\begin{array}{l}\text { empathy for attention to obstacles } \\
\text { and problems }\end{array}$ & \\
\hline demonstrate friendship & $\begin{array}{l}\text { expression about the value of the } \\
\text { employee and her or his } \\
\text { contribution to work }\end{array}$ & build a warm, friendly relationship \\
\hline $\begin{array}{l}\text { acceptance \& confirmation of } \\
\text { individual }\end{array}$ & $\begin{array}{l}\text { concern over the employee's needs } \\
\text { and objectives }\end{array}$ & \\
\hline $\begin{array}{l}\text { consideration of individual's } \\
\text { feelings }\end{array}$ & $\begin{array}{l}\text { interaction that provides time for } \\
\text { the employee to air his or her } \\
\text { feelings }\end{array}$ & \\
\hline
\end{tabular}


Managerial Coaching 79

APPENDIX B

MANAGER SURVEY FORM 


\title{
Managerial Coaching 80
}

\section{Managerial. Coaching Survey (Manager Form)}

\begin{abstract}
Section II: Each of the statements below describes a MANAGER'S COACHING BEHAVIOR. For each statement, you will mark two answers, ONE in Column A and ONE in Column B. For Column A, although you may have multiple coaching relationships, think of your response to each statement in terms of your general coaching experience. For Column $B$, think of your response to each statement in terms of what makes for effective coaching. If a statement is not applicable, DO NOT select and mark a response.
\end{abstract}

FOR COLUMN B: After completing Column A, read each statement below again-

1 - begin each sentence with: In order for coaching to be effective, a coach

must...

2- substitute "HIS/HER" for "MY"

3- mark how important a statement is as a measure of effective coaching

(The way it should be).

FOR COLUMN A: Complete this column first. Read each statement below -

1- begin each statement with: As a coach, l...

2- mark to what extent a statement reflects your current experience of coaching (The way it is).

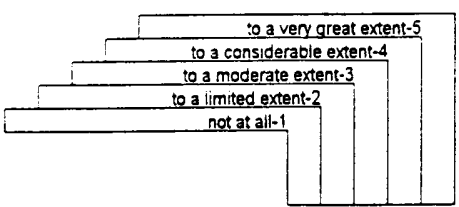

Column A

(The way it is)

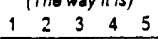

show interest in and concem ior MY coworkers' professional welfare and success

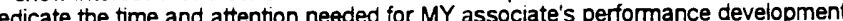
know the technical skills required of MY associate know MY associate's performance strengths and areas for improvement hold routine performance feedback sessions with MY associate encourage MY associate to take on challenging assignments and responsibilities help create an environment that fosters open communication encourage the exchange of direct and honest feedback with MY associate share important information and experiences when appropriate use 'good' and 'bad' events appropriately to further MY associate's learning and development view failures as steps to success take responsibility for MY own mistakes relate and work well with different types of people listen to MY associate carefully in order to understand his/her point of view clearly describe observations of MY associate's performance behaviors in the approprate manner and times explain important corporate perspectives, goals, and processes show how corporate's and MY associate's visions and values are linked larity performance goals and expectations in terms of objectives, standards and the desired measurable results model the performance behaviors expected of MY associate

consult MY associate's point of view in order to build mutual agreement guide MY associate toward the best decisions and solutions give MY associate the authority to make decisions and take action on his/her own when appropriate make the best of MY associate's abilities know what inspires MY associate about the work he/she does know how to get MY associate involved in his/her own work processes see to it that MY associate has the time, facilities and resources to accomplish his/her work goals see to it that MY associate has the time, facilities and resources to accomplish his/her development goals simultaneously meet diverse needs among MY associates work alongside of MY associate when necessary in order to help meet mutual goals express appreciation and value of MY associate's expertise and contributions acknowledge MY associate's achievements appropriately 


\section{Managerial Coaching 81}

Section III: Each of the statements below describes an ASSOCIATE'S COACHING BEHAVIOR. For each statement, you will mark two answers. ONE in Column A and ONE in Column B. For Column A, although you may have multiple coaching relationships, think of your response to each statement in terms of your general coaching experience. For Column B, think of your response to each statement in terms of what makes for effective coaching. If a statement is not applicable, DO NOT select and mark a response.

FOR COLUMN B: After completing Column A, read each statement below again 1 - begin each statement with: In order for coaching to be effective, an associate must take the initiative to...

2- substitute "HIS/HER COACH('S) for "ME" or "MY"

3- mark how important a statement is as a measure of effective coaching

(The way it should be)

FOR COLUMN A: Complete this column first. Read each statement below1- begin each statement with: My associate takes the initlative to...

2- mark to what extent a statement reflects your current experience of coaching (The way it is).

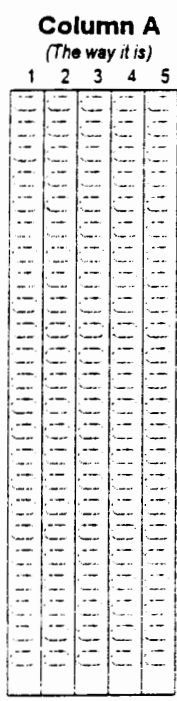

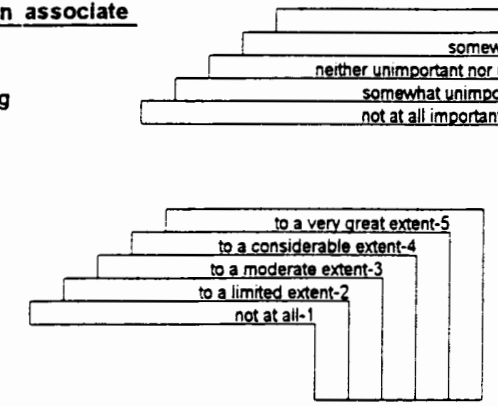

very important-5 mewhat importan

thertant-2

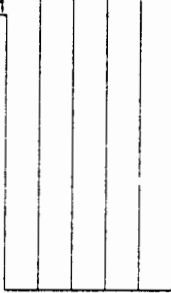

Column $\mathbf{B}$

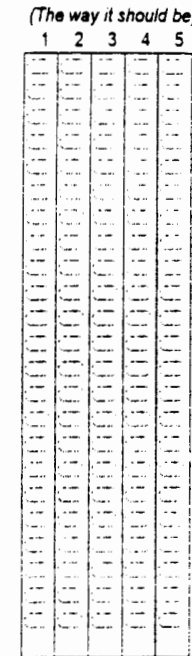

understand his/her work roles and tasks in terms of corporate and organizational goals and objectives clarify performance objectives, standards and how expected results are measured practice the corporate procedures and processes necessary in order to accomplish his/her goals dentify and consult with the appropriate people and resources in order to obtain critical information know his/her own performance strengths and areas for improvement solicit and weicome ongoing performance feedback from ME engage in ongoing development of his/her own knowiedge, skills and abilities create opportunities for himself/herse heip identify work-related problems and develop solutions help develop work strategies and prioritize tasks help improve work products and/or services make appropriate and timely decisions on his/her own be accountable for his/her professional behavior and work provide information and advice in his/her area of expertise to other coworkers support MY decisions and actions taken in the company's best interest relate and work well with other coworkers give feedback and support to other coworkers show interest in and concern for other coworkers' success in the company work with the client as a business partner understand his/her external clients' current and future needs and expectations provide important information, advice and support to his/her external clients understand his/her internal clients' current and future needs and expectations provide important information, advice and support to his/her internal clients 


\section{Managerial Coaching 82}

Section IV: Each of the statertients below describes a QUALITY OF COACHING. For each statement, you will mark two answers, ONE in Column A and ONE in Column B. For Column A, although you may have multiple coaching relationships, think of your response to each statement in terms of your general coaching experience. For Column $B$, think of your response to each statement in terms of what represents effective coaching. If a statement is not applicable. DO NOT select and mark a response.

FOR COLUMN B: After completing Column A, read each statement below againMark how important each statement is as a measure of effective, coaching (The way it should be)

FOR COLUMN A: Complete this column first. Read each statement belowMark to what extent you agree with a statement (The way it is).

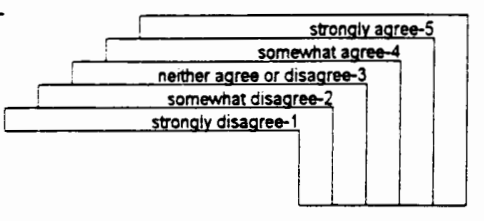

Column A

(The way it is)

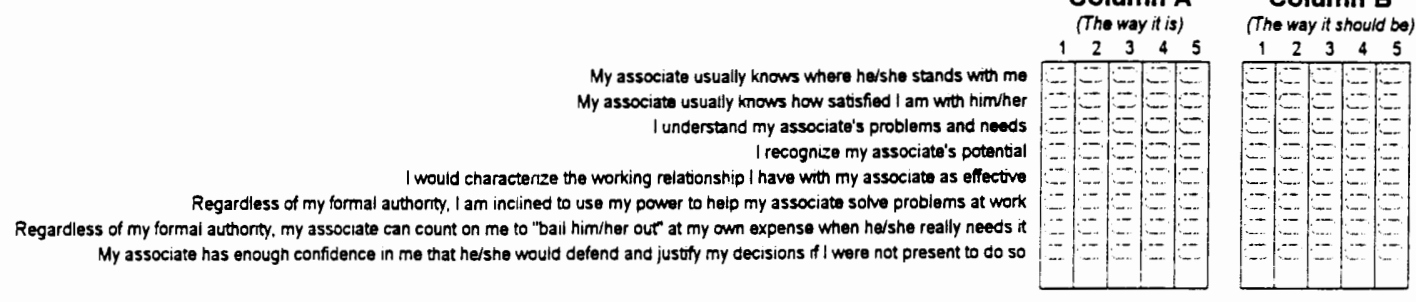

very important-5 mewhat important unimportant nor important-3 somewhat unimportantnet at allimportant-1

Section V: Think of the person with whom you can work least well. He/she may be someone you work with now, or may be someone you knew in the past. He/she does not have to be the person you like least well, but should be the person with whom you had the most difficulty in getting a job done. Describe this person as he/she appears to you according to the paired words below. For each pair of words, select and mark a response from 1 to 8 that best describes him/her.

Pleasant
Friendly
Rejecting
Heipful
Unenthusiastic
Tense
Distant
Cold
Cooperative
Supportive
Boring
Quarrelsome
Self-Assured
Efficient
Glcomy
Open


Managerial Coaching 83

APPENDIX C

ASSOCIATE SURVEY FORM 


\title{
Managerial Coaching Survey (Associate Form)
}

\begin{abstract}
Section It: Each of the statements below describes a MANAGER'S COACHING BEHAVIOR. For each statement, you will mark two answers, ONE in Column A and ONE in Column B. For Column A, think of your response to each statement in terms of your present coaching experience with your manager. For Column $B$, think of your response to each statement in terms of what makes for effective coaching. If a statement is not applicable, DO NOT select and mark a response.
\end{abstract}

FOR COLUMN B: After completing Column A, read each statement below again1- begin each sentence with: In order for coaching to be effective, a coach must...

2-substitute "THE ASSOCIATE('S)" for "ME", "MY" or "l"

3-mark how important a statement is as a measure of effective coaching (The way it should be).

FOR COLUMN A: Complete this column first. Read each statement below 1- begin each statement with: My coach...

2- mark to what extent a statement reflects your current experience of coaching (The way it is).

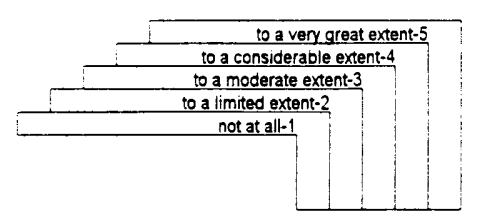

Column A

show(s) interest in and concern for his/her coworkers' professional welfare and success dedicate(s) the time and attention needed for MY performance development know(s) the technical skilis required of ME know(s) MY performance strengths and areas for improvement hold(s) routine performance feedback sessions with ME encourage(s) ME to take on challenging assignments and responsibilities help(s) create an environment that fosters open communication encourage(s) the exchange of direct and honest feedback with ME share(s) important information and experiences when appropriate use(s) 'good' and 'bad' events appropriately to further MY learning and development view(s) failures as steps to success take(s) responsibility for his/her own mistakes relate(s) and work(s) well with different types of people listen(s) to ME carefully in order to understand my (his/her) point of view clearly describe(s) observations of MY performance behaviors in the appropriate manner and time turn(s) sensitive issues and problems into positives explain(s) important corporate perspectives, goals, and processes show(s) how corporate's and MY visions and values are linked clarify(s) performance goals \& expectations in terms of objectives, standards \& the desired measurable results model(s) the performance behaviors expected of ME

consult(s) MY point of view in order to build mutual agreement guide(s) ME toward the best decisions and solutions give(s) ME the authority to make decisions and take action on my (his/her) own when appropriate
make(s) the best of MY abilities

know(s) what inspires ME about the work I do (he/she does) know(s) how to get ME involved in my (his/her) own work processes see(s) to it that I have (has) the time, facilities and resources to accomplish my (his/her) work goals see(s) to it that I have (has) the time, facilities and resources to accomplish my (his/her) development goals simultaneously meet(s) diverse needs among his/her associates work(s) alongside of ME when necessary in order to help meet mutual goals express(es) appreciation and value of MY expertise and contributions acknowledge(s) MY achievements appropriately

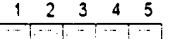

(The way it is)

Column B (The way it should be) $\begin{array}{lllll}1 & 2 & 3 & 4 & 5\end{array}$

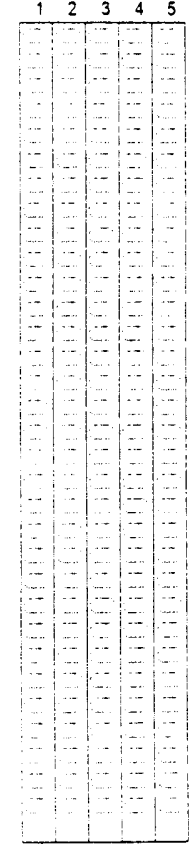


Section III: Each of the statements below describes an ASSOCIATE'S COACHING BEHAVIOR. For each statement, you will mark two answers, ONE in Column A and ONE in Column B. For Column A, although you may have multiple coaching relationships, think of your response to each statement in terms of your present coaching experience with your manager. For Column $B$, think of your response in terms of what makes for effective coaching. If a statement is not applicable. DO NOT select and mark a response.

FOR COLUMN B: After completing Column A, read each statement below again -

1 - begin each statement with: In order for coaching to be effective, an associate must take the initiative to..

2- substitute "HIS/HER" for "MY"

3- mark how important a statement is as a measure of effective coaching

(The way it should be) (The way it is).

FOR COLUMN A: Complete this column first. Read each statement below1 - begin each statement with: I take the initiative to...

2- mark to what extent a statement reflects your current experience of coaching

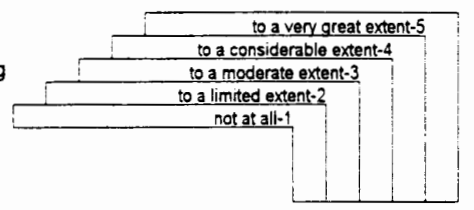

Column A

understand MY work roles and tasks in terms of corporate and organizational goals and objectives clarify performance objectives, standards and how expected results are measured practice the corporate procedures and processes necessary in order to accomplish MY goals identify and consult with the appropriate people and resources in order to obtain critical information know MY own performance strengths and areas for improvement solicit and weicome ongoing performance feedback from MY coach engage in ongoing development of MY own knowledge, skills and abilities create opportunities for MYself help identify work-related problems and develop solutions heip develop work strategies and prioritize tasks help improve work products and/or services make appropriate and timely decisions on MY own be accountable for MY professional behavior and work provide information and advice in MY area of expertise to other coworkers prov MY coach's decisions and actions taken in the company's best interest support MY coach's decisions and actions taken in the company's best interest
relate and work well with other coworkers
give feedback and support to other coworkers support MY coach's decisions and actions taken in the company's best interest
relate and work well with other coworkers
give feedback and support to other coworkers show interest in and concern for other coworkers' success in the company work with the client as a business partner understand MY external clients' current and future needs and expectations provide important information, advice and support to MY external clients understand MY internal clients' current and future needs and expectations

provide important information, advice and support to MY internal clients
(The way it is)

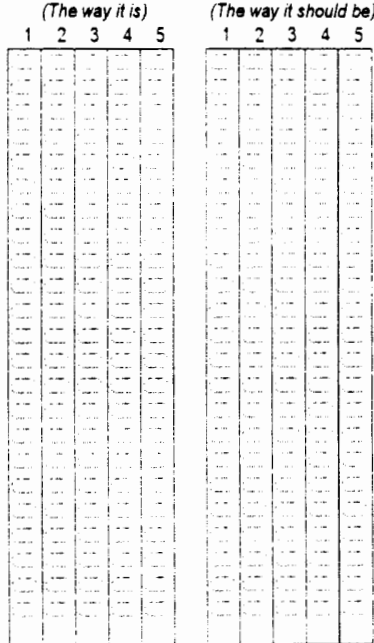

very important-5 recon not at all important-1 


\section{Managerial Coaching 86}

Section IV: Each of the statements below describes a QUALITY OF COACHING. For each statement, you will mark two answers, ONE in Column $A$ and ONE in Column B. For Column A, think of your response to each statement in terms of your present coaching experience with your manager. For Column B, think of your response to each statement in terms of what represents effective coaching If a statement is not applicable, DO NOT select and mark a response.

FOR COLUMN B: After completing Column A, read each statement below againMark how important each statement is as a measure of effective coaching

(The way it should be)

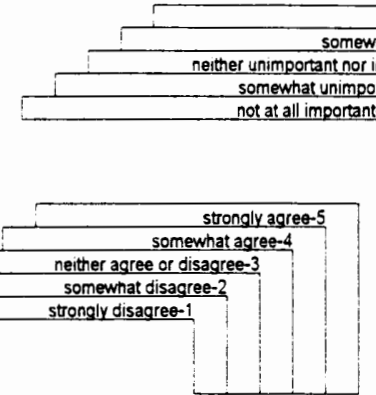

FOR COLUMN A: Complete this column first. Read each statement belowMark to what extent you agree with a statement (The way it is).
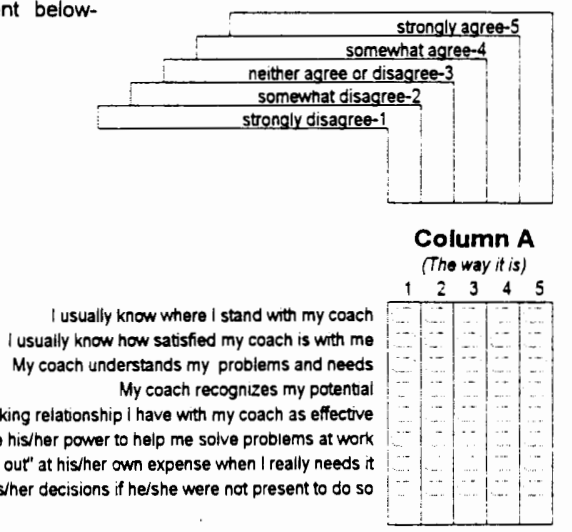

very important-5 at important-4 mportant-3

I usually know where I stand with my coach usually know how satisfied my coach is with me My coach understands my problems and needs My coach recognizes my potential I would characterize the working reiationship I have with my coach as effective Regardless of his/her formal authority. my coach is inclined to use his/her power to help me solve problems at work Regardiess of his/her formal authority I can count on my coach to "bail me out" at his/her own expense when I really needs it I have enough confidence in my coach that I would defend and justify his/her decisions if he/she were not present to do so 
APPENDIX D

CONTENT ANALYSIS SUMMARY/COACHING FRAMEWORK 


\section{COACHING IS A TWO-WAY ONGOING CONVERSATION THAT CONTINUALLY HELPS DEVELOP BOTH PERSONS' PROFESSIONAL SKILLS AND ABILITIES.}

\begin{tabular}{|c|c|}
\hline $\begin{array}{l}\text { The COACH: Facilitates mutual conversations in } \\
\text { order to share information, clarify goals and } \\
\text { exchange feedback }\end{array}$ & $\begin{array}{l}\text { The ASSOCIATE: Seeks to develop and } \\
\text { effectively apply his/her knowledge, skills } \\
\text { and abilities }\end{array}$ \\
\hline 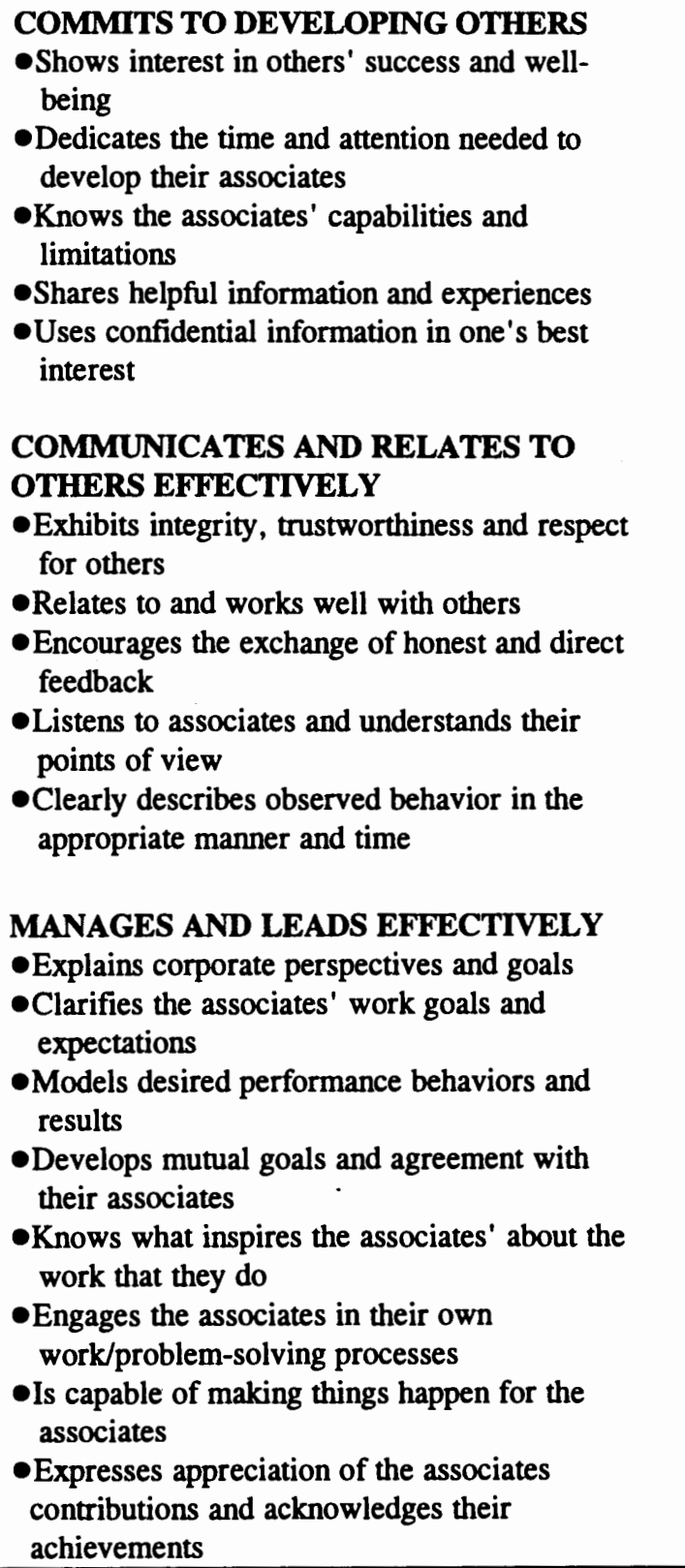 & $\begin{array}{l}\text { COMMITS TO DEVELOPING SELF } \\
\text {-Understands own roles and tasks in } \\
\text { terms of the corporate and } \\
\text { organizational goals and objectives } \\
\text { - Knows how to navigate in the } \\
\text { corporate environment } \\
\text { - Knows own performance strengths and } \\
\text { areas for improvement } \\
\text { - Invites and welcomes ongoing } \\
\text { performance feedback } \\
\text { - Engages in continual improvement of } \\
\text { technical and social skills } \\
\text { - Identifies and connects with } \\
\text { appropriate resources in order to } \\
\text { obtain critical information } \\
\text { - Creates opportunities for themselves } \\
\text { CONTRIBUTES EFFECTIVELY } \\
\text { - Heips develop work strategies and } \\
\text { prioritize tasks } \\
\text { - Helps identify problems and develop } \\
\text { solutions } \\
\text { - Makes appropriate and timely } \\
\text { decisions on his/her own } \\
\text { - Collaborates well with other team } \\
\text { members } \\
\text { - Gives helpful feedback to his/her } \\
\text { coach and other coworkers } \\
\text { - Seeks to understand the clients' current } \\
\text { and future needs } \\
\text { - Builds successful relations with clients } \\
\text { - Provides helpful information, advice } \\
\text { and support to clients }\end{array}$ \\
\hline $\begin{array}{l}\text { RESULTS: Continual development of managerial } \\
\text { and leadership skills in order to enhance the } \\
\text { effectiveness of others, self and the organization }\end{array}$ & $\begin{array}{l}\text { RESULTS: Self-directed, accountable } \\
\text { individual who continues to grow and } \\
\text { succeed }\end{array}$ \\
\hline
\end{tabular}




\section{APPENDIX E}

\section{E-MAIL REQUEST FOR RESEARCH PARTICIPANTS}

Initial Request Distributed to Managers Corporate-wide by Liaison

\section{Subject: CAN MANAGERS BE BETTER COACHES?}

If you are interested in enhancing your coaching skills as a manager and supporting a graduate student's research, then read on....

As a manager have you ever asked yourself, "How can I become a better coach of my direct reports?" "What impact does coaching have on the people I manage and the organization I work in?"

Recent research seems to indicate that the answers to these questions may best be obtained by consulting direct reports about their coaching experiences with their managers, and observations of the interactions between managers and direct reports.

With your participation in a masters student's thesis research, measures of effective coaching can be developed and used to improve your management skills. Debbie Petricek is a graduate student at Portland State University who wants to conduct her research in a high tech company. She would like managers to participate in one or more of the three research stages described below.

Please enter an "X" to the left of each stage in which you will be willing to contribute your feedback and return this message to...

STAGE I: Information Gathering

In order to gather information about coaching practices, a small group of managers, direct reports and their peers will be individually interviewed. When feasible, additional interviews and observations will be conducted with dyads while coaching is in progress. Individual interviews will involve three one-hour sessions per participant. Dyad interviews will involve two one-hour sessions during routine meetings. The maximum time per participation will be approximately five hours over a four-week period between late October and early November. Participant confidentiality will be protected throughout the research project. 
STAGE II: Pilot Study

Participants will anonymously respond to three short questionnaires that address employee demographics and coaching behaviors and outcomes. This survey will be administered in late November and will take about twenty minutes to complete.

STAGE III: Survey

Participants will anonymously respond to a series of questionnaires that address employee demographics and coaching-related phenomena. This survey will be administered in early December and will take about forty minutes to complete.

Your perspectives and comments on coaching activities and behaviors will help create a model of effective coaching for managers. In addition, the information shared from this study will provide important feedback to you for enhancing your own coaching skills and abilities.

Please respond by.... Your prompt response to this request is appreciated!

Thanks. 
Managerial Coaching 91

APPENDIX F

INFORMED CONSENT: INTERVIEW STAGE 


\section{Managerial Coaching Research: Interview Stage INFORMED CONSENT FORM}

I, , agree to take part in this research project about managerial coaching. The researcher, Debbie Petricek, has informed me that the purpose of this study is to develop an assessment tool for coaching. She has also offered to answer any questions I may have about the study at any time.

I understand that this research involves individual interviews about coaching experiences with coaches and coachees. The inquiry sessions will be prescheduled and conducted on company time. The total time needed from each participant is approximately three to four hours. I have been assured that efforts will be made to avoid disturbances in my work schedule and responsibilities.

I also understand that my acceptance or refusal to participate will not affect my relationship with my supervisor(s) and employer, and that my confidentiality will be protected. However, I am aware that there is a social risk inherent in research of this nature. It is possible that critical issues may rise and levels of sensitivity may increase in response to research-related activities. In order to help minimize any social risks and protect all participants' confidentiality, the researcher has recommended that I refrain from discussing the contents of the interviews with other employees.

I understand that, with consent, my interview will be audiotaped in order to assure accurate communications. Furthermore, I understand that any identities in the written and taped contents will be disguised in order to protect the respondents. The interview discourse be analyzed in order to identify effective coaching practices. Research findings will be shared with the participants as well as other members of participating organizations, and may be publicly reported and published. Ms. Petricek has promised that all the information I give will be kept confidential to the extent permitted by law. Upon completion of the study, the tapes and written documents will be stored and accessed only by the researcher her thesis advisor.

I understand that I do not have to take part in this study and may withdraw from the project at any time. I have read and understand the above information and agree to take part in this research project.

Date:

Participant's Signature:

Researcher's Signature:

Phone: $\underline{x x x / x x x-x x x x}$

E-mail: psuxxxxx@oodin.cc.pdx.edu

If you have any concerns or questions about this study, please contact: Human Subjects Research Review Committee, Office of Research and Sponsored Projects, 105 Neuberger Hall, Portland State University, 503/725-3417. 


\section{APPENDIX G}

\section{E-MAIL ANNOUNCEMENT OF SURVEY STUDY}

To: (manager interviewed)

Below is an announcement of my study that you can copy to your direct reportsThanks for your assistance, Debbie

\section{Subject: WHAT MAKES FOR EFFECTIVE COACHING?}

If you are interested in enhancing your coaching experience and supporting a graduate student's research, then read on...

Currently, in your company, I am conducting a series of interviews with several managers about managerial coaching. Soon, I plan to interview some direct reports in order to gather their perspectives of coaching as well. These efforts are part of a thesis project and will result in the development of a tool for assessing coaching practices.

If you are interested and willing to share some of your coaching experiences and beliefs, please relay your name, phone and e-mail to my e-mail address below. ALL INFORMATION YOU SHARE WILL BE CONFIDENTIAL. YOUR MANAGER OR OTHER EMPLOYEES WILL NOT KNOW THE STATUS OF YOUR PARTICIPATION. I will conduct two to three interviews, each about an hour long, with a direct report. The interviews will be conducted on company time and will be scheduled at his or her convenience.

Thank you for your reply, Debbie Petricek (xxx) xxx-xxxx

Portland State University E-mail: PSUxxxxx@odin.cc.pdx.edu 


\section{APPENDIX H \\ PROTOCOL OF INITIAL INTERVIEW AGENDA}

Do you believe coaching occurs in your company?...Give me an example of why you think so.

Are you familiar with any specific coaching programs or models... what guidelines, manuals do you follow?

Would you say that you (coach others/are coached) in this work environment...formally or informally? Describe your coaching partner in terms of job position, rank, etc.

How do you experience coaching routines...are meetings scheduled, does it occur on-the-job, or is it more casual conversations from time to time?

How would you define the concept of coaching according to what exists here?

How is coaching different than...management?...leadership?...mentoring?

What do you suppose are the purposes of coaching? (Why is coaching important to your company?)

Explain what coaching is about? (What is it exactly...when someone is coaching?)

Who (do you coach/coaches you (e.g., manager, peer, subordinate)?

(Do you coach/Are you coached by) more than one person? How many?

(Do you coach others/Have you been coached by others) differently? Who?

Do you associate coaching with...directive management?...disciplinary action (correction)?

What are some of the desirable traits of coaches? 
What are some of the desirable traits of coachees?

What are some of the expectations for those being coached?

How do coaching partners benefit from coaching?

What are some of the outcomes of coaching?

In your opinion, what makes for successful coaching?

What are some of the organizational barriers of coaching? 


\title{
APPENDIX I
}

\section{INTERNAL SUBJECT MATTER EXPERTS' SORTING}

\author{
Coaching Dimensions, Categories, \& Best Measures
}

\section{Dimension: COACH TRAITS AND VALUES}

\section{Category: Coach as Manager}

Best Measures:

Coaches have simultaneously managed many direct reports in different tasks and directions.

Coaches have varied their management style approach according to the direct report.

Coaches have thoroughly understood their own managerial roles and responsibilities.

Coaching has helped provide the structure and direction needed in order for direct reports to understand and perform their jobs.

Coaches have spent time with their direct reports informally discussing the managerial goals and expectations for direct reports.

\section{Category: Coach as Model}

Best Measures:

Coaches have demonstrated integrity.

Coaches have set behavioral examples for their direct reports.

Coaches have been honest and trustworthy.

\section{Dimension: ENVIRONMENT}

\section{Category: Coaching for Organizational Understanding}

[no best measure identified]

\section{Category: Communication: A Critical Coaching Tool}

Best Measures:

Coaching has helped demonstrate to direct reports how to communicate and work with other team/group members.

\section{Category: Empowerment Through Coaching}

Best Measures:

Coaches have acknowledged their direct reports' contributions and achievements.

Coaching has helped direct reports take ownership of their professional behavior and growth.

Coaches have expressed value for their direct reports' expertise and opinions.

\section{Category: Coaching to Create a Win/Win Environment}

Best Measures:

Coaches have created an open and welcoming environment.

Coaches have worked closely with others to create an even more satisfying and productive work environment. 


\section{Dimension: PERFORMANCE MANAGEMENT}

\section{Category: Coaching for Customer Focus}

Best Measures:

Coaching has helped direct reports understand the customers' future needs and desires.

Coaching has helped to clarify customer requests and expectations.

\section{Category: Problem Solving Through Coaching}

Best Measures:

Coaching has helped to guide direct reports toward the best solutions.

Coaching has helped direct reports to identify problems and develop strategies and solutions.

\section{Category: Coaching Through Feedback}

\section{Best Measures:}

Coaches have clearly communicated the observed behaviors and performances to each direct report, respectively.

Coaching has helped foster immediate feedback on the behaviors of direct reports.

\section{Category: Coaching for Performance}

Best Measures:

Coaching has helped direct reports develop specific action plans and goals related to their jobs/performances.

Coaching has helped provide regular performance feedback.

Coaching has helped to clarify the standards of performance for direct reports.

\section{Dimension: CAREER DEVELOPMENT}

\section{Category: Ongoing Professional Growth \& Development of the Coach}

Best Measures:

Coaching has helped to contribute to both the direct reports' as well as the managers' growth and effectiveness.

\section{Category: Development of Employee Through Coaching}

\section{Best Measures:}

Coaches have been involved in the development processes of their direct reports.

Coaches have demonstrated concern for the professional development and effectiveness of their direct reports. 


\title{
What Makes For Effective Coaching?
}

\author{
Learn how managers and direct reports can enhance their \\ coaching relationships \\ $\&$ \\ Enter the 'spirit of coaching' sweepstakes' \\ First Prizes (two): Overnight package at "Sea Quest Bed \& Breakfast" on the Oregon coast ${ }^{2}$ \\ Second Prizes (two): On-site chair massages for team/group of six \\ Third Prizes (two): Session with stress reduction consultant ${ }^{3}$ \\ \&
}

Support a graduate student's research

Help identify how managers and direct reports alike can contribute to successful coaching relationships. Your participation in a Managerial Coaching Survey (approx. 30 min.) will help illustrate both current coaching practices and what makes for effective performance coaching.

The survey is based on interviews held with a group of volunteer managers and direct reports from a Portland based company in order to describe the 'spirit of coaching' that has swept the workplace. This survey serves as a two-way communication tool for managers and direct reports to collectively share their feedback about coaching roles and practices. To demonstrate the value of this tool, the survey will be administered across companies. Grouped, not individual, survey feedback will be shared. The confidentiality of all participants and companies will be protected.

To obtain the hard copy survey, forward your mailing address to the researcher's, Debbie Petricek, e-mail: psuxxxxx@odin.cc.pdx.edu or phone \#(xxx) xxx-xxxx. Please ask for either the MANAGER FORM of the survey if you are a manager who provides coaching to direct reports or the ASSOCIATE FORM of the survey if you are a direct report who is coached by a manager. As a participant in the survey your name will be automatically entered for the sweepstakes drawings.

\footnotetext{
'all prizes are transferrable and subject to expiration dates

${ }^{2}$ overnight packages available Sunday through Thursday nights

${ }^{3}$ includes massage, postural analysis, and body alignment
} 
Managerial Coaching 99

APPENDIX I

INFORMED CONSENT: SURVEY STAGE 


\section{Managerial Coaching Research: Survey Stage INFORMED CONSENT FORM}

I, about managerial coaching. I understand that my acceptance or refusal to participate will not affect my relationship with my employer, supervisor(s) or other coworkers.

The researcher, Debbie Petricek, has informed me that the purpose of this study is to develop an assessment tool for coaching. I understand that the research involves completing and returning a series of questions about my coaching experiences and beliefs. One of the sets of questions asks for demographic information like my age, ethnicity, job position and tenure. I understand that when the researcher receives my completed survey she will separate the signed consent form from the survey portion in order to protect my confidentiality. I understand that the information I share will be kept confidential to the extent permitted by law, and will be accessed only by the researcher and her thesis advisor.

I also understand that to ensure the confidentiality of all participants and success of the research, it is best not to discuss the survey contents with other coworkers. I understand that survey results at the group level will be shared with the participants and their associated companies; no individual surveys will be shared. In addition, I am aware that the research results may be publicly reported and published.

Ms. Petricek has offered to answer any questions I may have about the study. I am aware that I do not have to take part in this study and may withdraw from the project at any time. I have read and understand the above information and agree to take part in this research project.

Date: Participant's Signature

Researcher's Signature: Phone: $\underline{\operatorname{xxx} / x x x-x x x x}$ Review Committee, Office of Research and Sponsored Projects, 105 Neuberger Hall, Portland State University, 503/725-3417. 
Managerial Coaching 101 APPENDIX L

SURVEY INSTRUCTION PAGE 


\section{Managerial Coaching Survey}

This survey will help illustrate both current and ideal coaching practices according to the perceptions of managers and associates across innovative work environments. Responses will be collected from individuals who are involved in coaching relationships within their respective companies. Collective responses will yield composite profiles of coaching that will help clarify the nature of coaching and how managers and associates might enhance their coaching experiences. Survey responses will be entered in confidence into a database for statistical analysis as partial fulfillment for Debbie Petricek's Masters Thesis at Portland State University.

Because survey participants represent a variety of corporate cultures and languages, and because there are varying connotations of coaching, the terms used in this survey are clarified below:

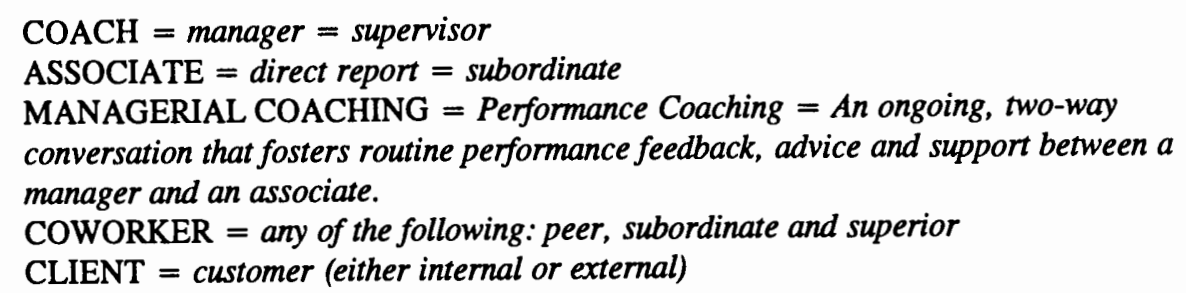

\section{INSTRUCTIONS:}

1. Make sure you complete and return the appropriate survey form by

The following survey comes in both 'manager' and 'associate' forms. If you will be responding from the manager/coach perspective you will complete the MANAGER FORM. If you will be responding from the direct report/subordinate perspective you will complete the ASSOCIATE FORM. In either case, you will be responding to statements about both coach and associate behaviors.

2. Read, sign and return the enclosed consent form along with the survey

3. Take as much time as you need to complete the survey (approximately 30 minutes)

4. Fill out the Section I: Demographic Questionnaire on Page 1 before completing the other sections

5. Review the example/directions on Page 2 as well as the instructions with each section in order to accurately select and mark your responses

6. Use no. 2 pencil only. DO NOT make any marks outside of the bubbles. You may forward additional comments and suggestions to the researcher on a separate piece of paper along with the return of your completed survey.

7. After completing the survey either return it to the researcher in the self-addressed stamped envelope

8. You may contact the researcher at any time to clarify instructions or contents: Debbie Petricek, by phone (xxx) xxx-xxxx or by e-mail psuxxxxx@odin.cc.pdx.edu 
Managerial Coaching 103

APPENDIX M

DEMOGRAPHIC QUESTIONNAIRE 


\section{Managerial Coaching Survey (Manager and Associate Form)}

\section{Section I: DEMOGRAPHIC QUESTIONNAIRE}

Demographic information is instrumental in understanding organizational research. You are encouraged to complete this section so that the researcher may best describe the general characteristics of the survey participants and better understand how these characteristics relate to coaching practices. Your confidentiality will be protected; your responses will NOT BE linked to your personal identity. In addition, your company's confidentiality will be protected.

\begin{tabular}{|c|c|}
\hline Company Name: & \\
\hline Total time at your company: & mos \\
\hline Your job title: & \\
\hline Total time in this position: & $\operatorname{mos}$ \\
\hline Main group you work for (check one): & $\begin{array}{l}\text { Business Technology } \\
\text { Engineering } \\
\text { - Services } \\
\text { - Marketing } \\
\text { _ Human Resources } \\
\text { Huther/Specify: }\end{array}$ \\
\hline Total time in this group: & $\operatorname{mos}$ \\
\hline Total time in this career track: & $\operatorname{mos}$ \\
\hline Highest level of education (check one): & $\begin{array}{l}\text { high school } \\
\text { Doctorate }\end{array}-$ some college $\quad$ BA/BS _Masters \\
\hline Gender: & female \\
\hline Age: & yrs \\
\hline $\begin{array}{l}\text { Race/Ethnicity (check one of the following categories that } \\
\text { hest describes you): }\end{array}$ & 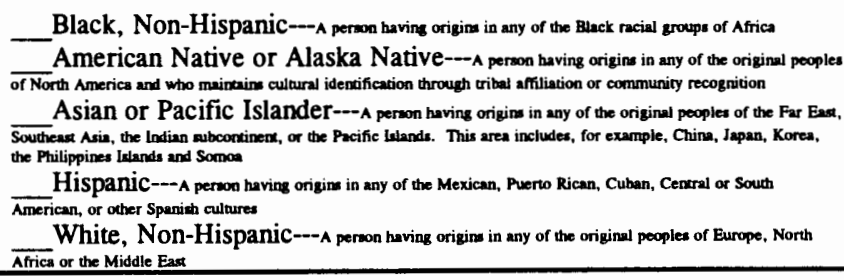 \\
\hline 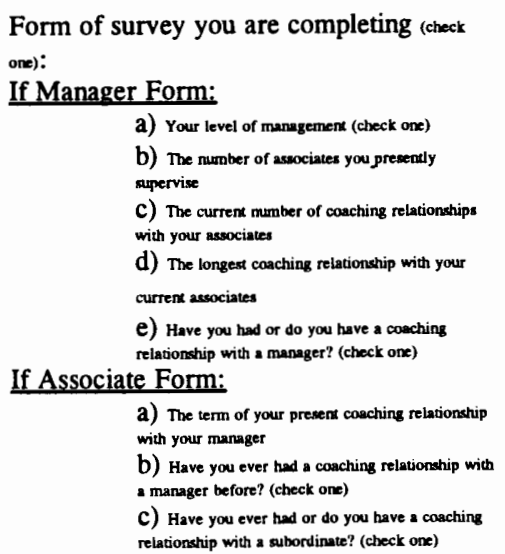 & 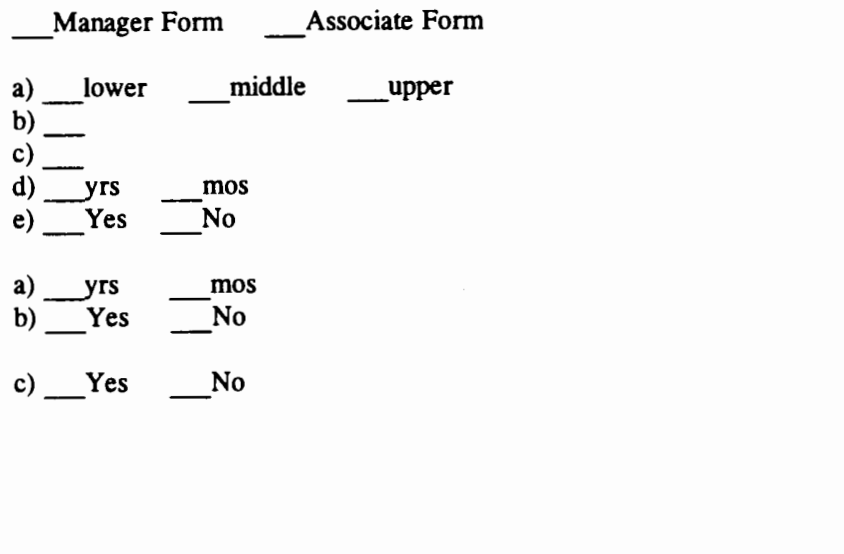 \\
\hline
\end{tabular}


Managerial Coaching 105

\section{APPENDIX N}

CORRESPONDING COACHING AND MANAGEMENT PRACTICES 
Managerial Coaching 106

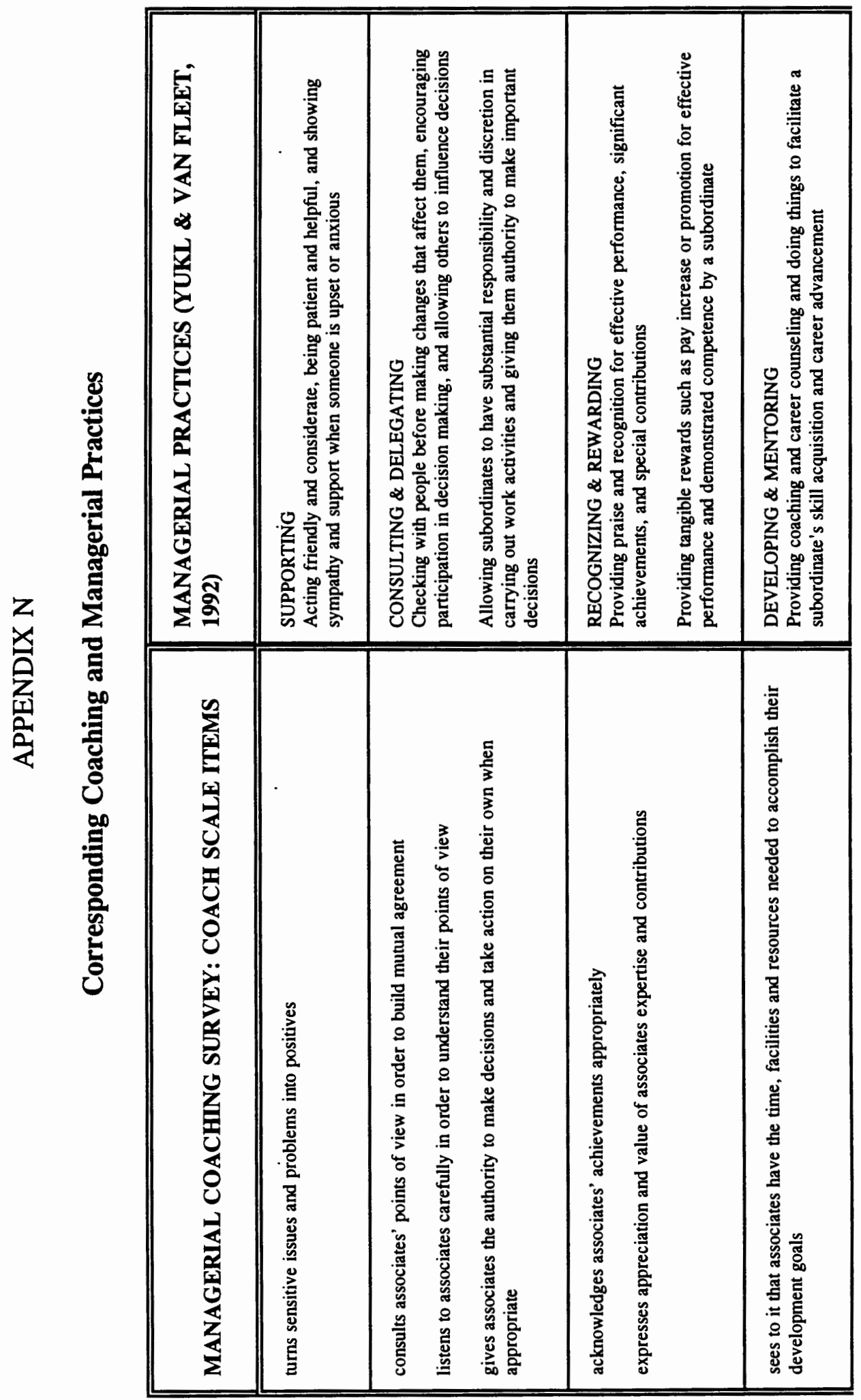




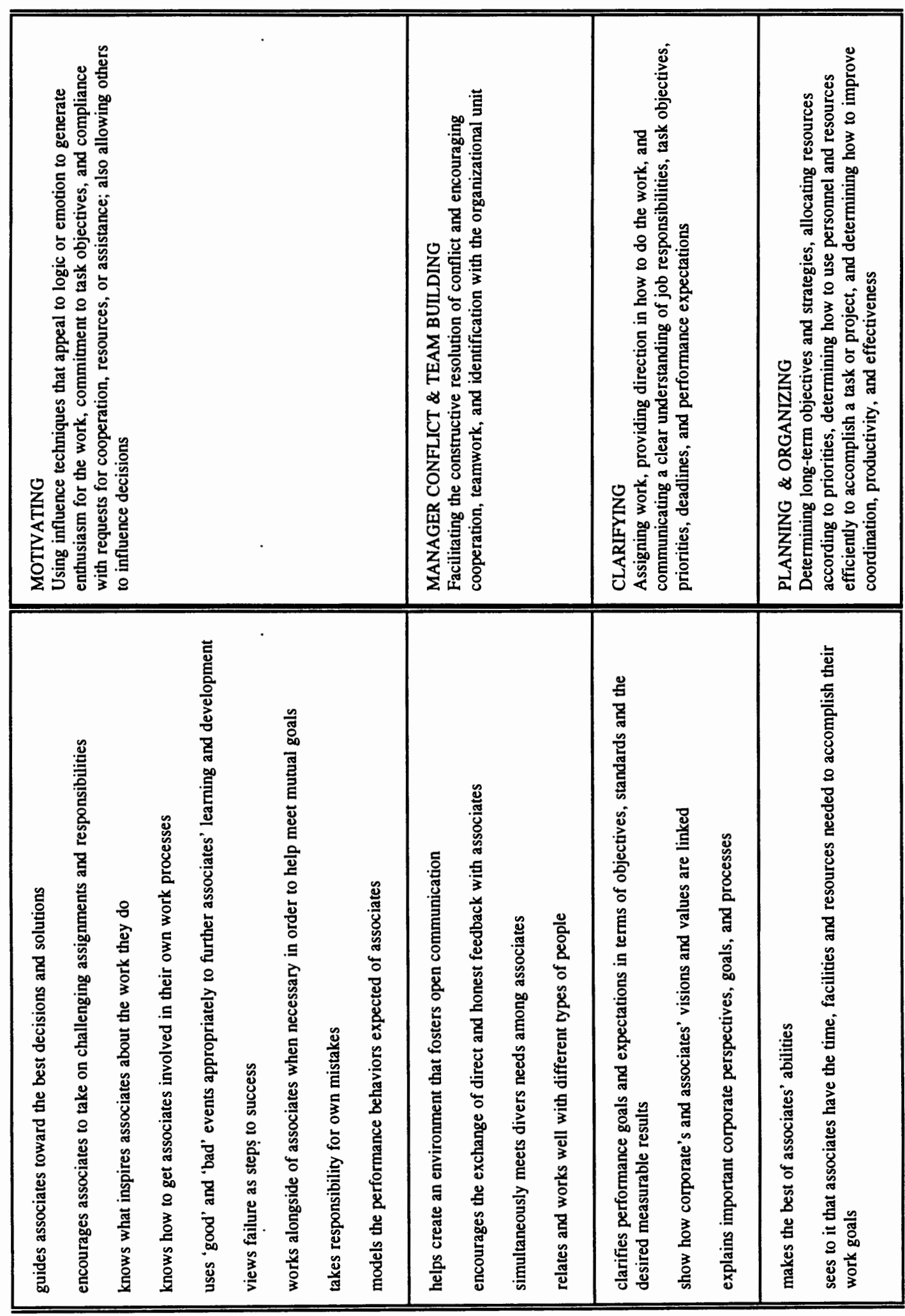


Managerial Coaching 108

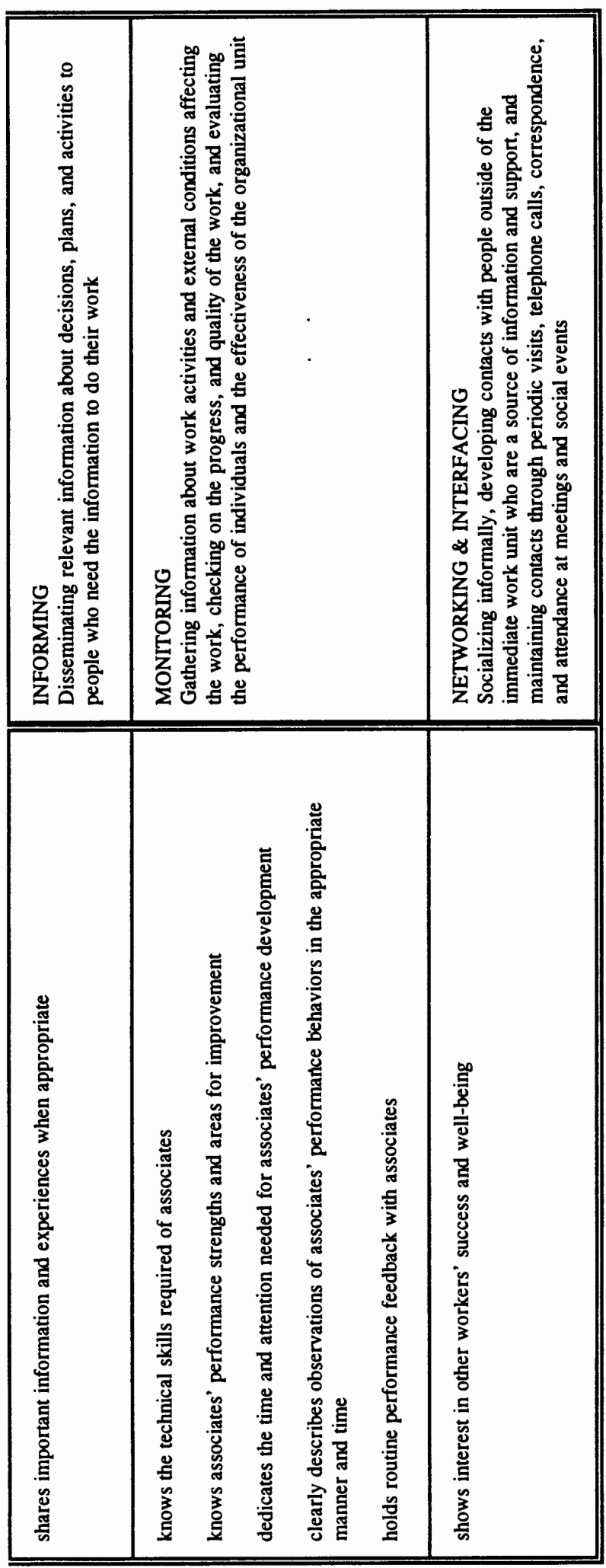

